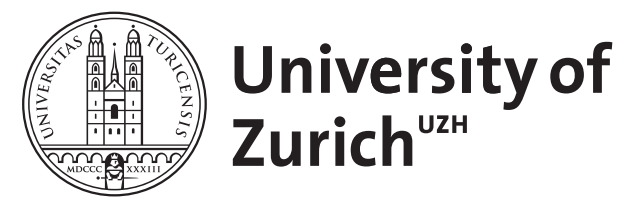

\title{
Modeling multiple sclerosis in laboratory animals
}

\author{
Schreiner, B ; Heppner, F L ; Becher, B
}

\begin{abstract}
Inflammatory demyelinating disease of the central nervous system is one of the most frequent causes of neurological disability in young adults. While in situ analysis and in vitro models do shed some light onto the processes of tissue damage and cellular interactions, the development of neuroinflammation and demyelination is a far too complex process to be adequately modeled by simple test tube systems. Thus, animal models using primarily genetically modified mice have been proven to be of paramount importance. In this chapter, we discuss recent advances in modeling brain diseases focusing on murine models and report on new tools to study the pathogenesis of complex diseases such as multiple sclerosis.
\end{abstract}

DOI: https://doi.org/10.1007/s00281-009-0181-4

Posted at the Zurich Open Repository and Archive, University of Zurich ZORA URL: https://doi.org/10.5167/uzh-26538

Journal Article

Published Version

Originally published at:

Schreiner, B; Heppner, F L; Becher, B (2009). Modeling multiple sclerosis in laboratory animals. Seminars in Immunopathology, 31(4):479-495.

DOI: https://doi.org/10.1007/s00281-009-0181-4 


\title{
Modeling multiple sclerosis in laboratory animals
}

\author{
Bettina Schreiner • Frank L. Heppner • \\ Burkhard Becher
}

Received: 12 June 2009 / Accepted: 13 August 2009 /Published online: 3 October 2009

(C) Springer-Verlag 2009

\begin{abstract}
Inflammatory demyelinating disease of the central nervous system is one of the most frequent causes of neurological disability in young adults. While in situ analysis and in vitro models do shed some light onto the processes of tissue damage and cellular interactions, the development of neuroinflammation and demyelination is a far too complex process to be adequately modeled by simple test tube systems. Thus, animal models using primarily genetically modified mice have been proven to be of paramount importance. In this chapter, we discuss recent advances in modeling brain diseases focusing on murine models and report on new tools to study the pathogenesis of complex diseases such as multiple sclerosis.
\end{abstract}

Keywords Autoimmunity · Immunopathology EAE · TH17 · Cytokines · TH1 · IL-12 · IL-23 · IL-18 · CD8 · CTL · Gene targeting $\cdot$ Transgenic $\cdot$ Mus musculus $\cdot$ Animal models $\cdot$ In vivo $\cdot$ Multiple sclerosis

\section{Experimental autoimmune encephalomyelitis-the gold standard}

Mode of induction

Experimental autoimmune encephalomyelitis (EAE) was first described and established as an important model of

B. Schreiner $\cdot$ B. Becher $(\bowtie)$

University of Zurich,

Zurich, Switzerland

e-mail: burkhard.becher@neuroimm.uzh.ch

F. L. Heppner

Charité-Universitätsmedizin Berlin,

Berlin, Germany central nervous system (CNS) autoimmune inflammation over 50 years ago [1]. EAE can be actively induced in susceptible inbred mice like SJL mice by immunization with mouse spinal cord homogenate [2], myelin basic protein (MBP; [3]), proteolipid protein (PLP; [4]) or peptides corresponding to the major encephalitogenic regions of MBP $\left(\mathrm{MBP}_{84-104}\right)$, PLP (PLP ${ }_{139-151}$ or $\mathrm{PLP}_{178-191}$ ), or myelin oligodendrocyte glycoprotein $\left(\mathrm{MOG}_{92-106}\right)$ in complete Freund's adjuvant (CFA). MOG makes up less than $0.5 \%$ of all myelin proteins and is situated on the surface of myelin sheaths. $\mathrm{MOG}_{35-55}$ peptide is strongly encephalitogenic in C57BL/6 mice, the strain providing the genetic background of most transgenic mice. Disease induction with intact MBP or $\mathrm{MBP}_{84-104}$ in SJL mice, and likewise with $\mathrm{MOG}_{35-55}$ in C57BL/6 mice, requires the use of pertussis toxin (PTX) as part of the induction regimen. PTX has been hypothesized to facilitate immune cell entry into the CNS [5, 6]; however, PTX has other biological effects that could contribute to its activity in EAE, such as breaking $\mathrm{T}$ cell tolerance and promoting clonal expansion and cytokine production by $\mathrm{T}$ cells [7-9]. In most murine EAE models, after a prodromal interval of 10-20 days, paralysis of tail and hind legs, progressing to the forelimbs, and weight loss develop, reflecting preferential targeting of inflammation to the spinal cord and to some extent the cerebellum (referred to as "classic EAE"). Accordingly, the scoring system is based primarily on motor deficits resulting from spinal cord lesions. However, enhanced brain inflammation and atypical clinical variations have been described in murine models using certain strain/ antigen combinations or a background of genetic interferon (IFN)- $\gamma$ deficiency $[10,11]$. Factors that can influence the manifestation of disease are age, gender, and season at immunization $[12,13]$, the preparation and physical 
structure of antigen/adjuvant emulsions [14, 15], the species origin of the antigen [16], and epigenetic factors [17]. The disease course of EAE depends on the strain, immunogen, and use of PTX [18]. In the SJL $\left(\mathrm{H}-2^{\mathrm{s}}\right)$ mouse strain, EAE displays a relapsing-remitting clinical course (RR-EAE), while in C57BL/6 $\left(\mathrm{H}-2^{\mathrm{b}}\right)$ or $\mathrm{PL} / \mathrm{J}$ and B10.PL $\left(\mathrm{H}-2^{\mathrm{u}}\right)$ mouse strains, the disease is chronicprogressive (C-EAE) or acute monophasic, respectively. Alternatively to direct induction, EAE can also adoptively be transferred to naïve mice by injection of in vitro neuroantigen-activated $\mathrm{T}$ cells isolated from primed donors [19]. The most common adoptive transfer models involve major histocompatibility complex (MHC)-class-IIrestricted $\mathrm{CD} 4+\mathrm{T}$ helper $\left(\mathrm{T}_{\mathrm{H}}\right)$ cells [20], while only a few reports describe EAE transfer by CD8+ T cells [21, 22]. Many of the pathogenic CD4 $+\mathrm{T}_{\mathrm{H}}$ cells respond to activation by secreting IFN- $\gamma$ and tumor necrosis factor (TNF)- $\alpha$, but not interleukin (IL)-4 and IL-5, qualifying them as $\mathrm{T}_{\mathrm{H}} 1$ cells. Recent studies, however, suggest that this population includes a subset of $\mathrm{CD} 4+\mathrm{T}_{\mathrm{H}}$ cells that preferentially produces IL-17 $\left(\mathrm{T}_{\mathrm{H}} 17\right.$ cells); by modifying $\mathrm{T}$ cell effector functions in vitro before transfer, Langrish and colleagues confirmed that IL-23-driven IL- $17^{+} \mathrm{T}$ cells are highly encephalitogenic [23]. It therefore currently appears that both $\mathrm{T}_{\mathrm{H}} 1$ and $\mathrm{T}_{\mathrm{H}} 17$ cells have pathogenic potential [24]. Another way of manipulating the myelinspecific $\mathrm{T}$ cells in vitro before transfer is the labeling by genetic markers or fluorescent proteins/dyes, so that the autoreactive $\mathrm{T}$ cells can be traced in the recipient $[25,26]$.

No spontaneous and naturally occurring animal models of spontaneous EAE exist. However, $\mathrm{T}$ cell receptor (TCR) transgenic mice have been generated that do not require peptide priming and strong immune adjuvants but spontaneously develop EAE with variable incidence. Although the immunological repertoire in TCR transgenic mice is significantly altered and biased towards enhanced antigen-specific responses and alternative mechanisms of immune regulation $[27,28]$, studies using such transgenic models have contributed significantly to the understanding of the pathogenesis of CNS autoimmunity. Various TCR transgenic models of EAE on different genetic backgrounds exist, including humanized mice carrying human leukocyte antigen (HLA) class II molecules associated with multiple sclerosis (MS) susceptibility and TCR [2931]. Interestingly, HLA-DRB $1 * 0401$-restricted $\mathrm{MBP}_{111-129^{-}}$ specific humanized TCR transgenic mice display clinical signs of inflammatory demyelination in brain stem and cranial nerve roots, like dysphagia in addition to ascending paralysis typical of EAE [31]. 19G B10.PL $\left(\mathrm{H}-2^{\mathrm{u}}\right) /$ $\mathrm{MBP}_{\mathrm{Ac} 1-11}$, [27], 5B6 SJL $\left(\mathrm{H}-2^{\mathrm{s}}\right) / \mathrm{PLP}_{139-151}$ [32], and 2D2 C57BL/6 (H2- $\left.{ }^{\mathrm{b}}\right) / \mathrm{MOG}_{35-55}$ TCR transgenics [33] are spontaneous models utilizing mouse MHC class II restriction elements. The clinical spectrum displayed varies from classical hind limb paralysis to isolated optic neuritis (2D2 TCR transgenics in the C57BL/6 strain). A large percentage of $\mathrm{MOG}_{35-55}$ TCR transgenic mice crossed to MOG-specific immunoglobulin heavy chain knock-in animals spontaneously develop a Devic-like, opticospinal disease [34, 35].

\section{Pathogenesis (priming and CNS invasion)}

Classical models of EAE are mainly driven by MHCclass-II-restricted CD4+ T lymphocytes [36-38]. Active and passive induction protocols both activate peripheral myelin-specific CD4+ T cells that have escaped immune tolerance and circulate in the periphery of naïve animals (reviewed in [39]). During the induction phase of actively induced $\mathrm{EAE}$, myelin-reactive $\mathrm{CD} 4+\mathrm{T}$ cells are primed and expand in the peripheral lymphoid organs. In contrast, in the adoptive transfer model of EAE, disease is induced by the peripheral introduction of a preactivated population of myelin-epitope-specific CD4+ T cells to a naïve mouse. The effector phase involves migration of activated myelinspecific $T$ cells to the CNS, where they cross the bloodbrain barrier (BBB). CNS-infiltrating CD4+ T cells require myelin peptides presented by local antigen-presenting cells (APCs) for full reactivation [40, 41]. Recently, also dendritic cells (DCs) have been demonstrated to be the initial APCs for encephalitogenic T cells to recognize their target antigen (Ag)/organ [42, 43]. The reactivated CD4+ $\mathrm{T}$ cells then initiate a cascade of events, including the secretion of chemokines, that recruit predominantly macrophages to the site of inflammation. Proinflammatory cytokines secreted by macrophages, such as TNF- $\alpha$ and IL-1, are important for both perpetuating inflammation and contributing to CNS tissue damage [44]. Microglia are also activated in EAE and blocking microglial activation suppresses the development of EAE, supporting their pathogenic role in CNS autoimmune disease [45-48]. The function of astrocytes in disease pathogenesis remains unclear, as they show proinflammatory activity by producing neurotoxic mediators, cytokines, and chemokines but also exert neuroprotective functions by providing neurotrophic factors (reviewed in [49-51]). After CNS tissue is damaged, epitope spreading is believed to occur by the release and subsequent presentation of endogenous myelin epitopes by local APCs [26, 52] and has been shown to mediate clinical relapses in certain EAE models [53, 54].

Mouse, rat, monkey background

EAE is mainly studied in the highly reproducible murine model, as mice are inbred and a genetically homogenous population. Furthermore, transgenic and targeted gene deletion murine models are abundant, 
and numerous reagents are available that can be used to dissect the pathogenic mechanisms in EAE. Nevertheless, EAE has been replicated in a wide range of species, and the different species and strains offer different advantages. EAE induced in rabbits or guinea pigs with CNS myelin is similar to MS in that inflammation occurs in both the brain and spinal cord $[55,56]$. To investigate the contribution of demyelinating antibodies, EAE models in guinea pig [57], common marmoset [58], and certain rat and mouse models [16, 59] have been proven to be useful.

EAE is induced in the marmoset by immunization with CNS tissue homogenate or recombinant MOG in CFA (reviewed in [60]) and provides a disease model that reproduces several clinical and pathological features of MS. Adoptive and passive transfer experiments indicate that, similar to MOG-induced EAE in the rat, synergism between encephalitogenic $\mathrm{T}$ cells and demyelinating antibodies is required for full lesion formation [58, 61]. In spite of variable disease induction in the outbred marmoset species and limited availability of reagents, the marmoset model may have some value for drug testing considering that it is phylogenetically closer to humans than rodents.

Histopathological findings - man versus mouse

Histopathological changes seen in EAE appear to represent a stereotypic response of the CNS to autoimmune damage. While EAE, as many other disease models, certainly is not a full mirror image of MS, it comes pretty close to what can be seen in human MS lesions. However, the clinical features, including the pattern of disease progression and the histopathology, may vary depending on (1) the species in which disease is provoked as well as (2) the approach of EAE induction (for review, see [62]).

Early and/or acute MS lesions in humans are characterized by demyelination (Fig. 1a, b), extensive macrophage invasion (Fig. 1c, d), perivascular and parenchymal $\mathrm{T}$ cell infiltrates (Fig. 1g, h), and few B cells/plasma cells as well as relative axonal preservation. While ongoing remyelination next to demyelination is a typical feature of active MS lesions [63], based on the myelin loss, extent of oligodendrocyte preservation, and composition of the inflammatory infiltrates, four distinct - admittedly descriptive - histopathological patterns of acute MS lesions have been suggested [64] and await final clinical validation. In brief, common feature of these acute lesions is the predominance of macrophages, which are $\sim 10$ times more frequent than, e.g., T cells (the latter are mainly of the CD8+ phenotype). On top of which, some lesions (referred to as pattern II) display activated complement on dying myelin sheaths and in macrophages, while others (so-called pattern III) are described to have a preferential loss of the myelin-associated glycoprotein (for review, see [65]). Recent data also point to a crucial role of $\mathrm{DCs}$, which due to their close proximity to invading $\mathrm{T}$ cells adjacent to CNS vessels (Fig. 1f, g, h) seem to be crucial APCs in conferring CNS inflammation of encephalitogenic $\mathrm{T}$ cells [42]. In contrast to acute MS lesions, chronic MS plaques display extensive and sharply demarcated white matter lesions with variable axonal loss and significant fibrillary astrogliosis; due to only few residual lymphocytes and macrophages/microglia, these chronic lesions appear to be "burnt out" (for review, see [65]).

Acute EAE lesions in mice-the species which we primarily refer to-histopathologically resemble the perivascular macrophage-/microglia-rich inflammatory pattern of acute/chronic active MS lesions in humans (Fig. 2), while severe demyelination is seen rather in chronic relapsing EAE models (for review, see [62]).

Due to the high reproducibility of EAE lesions with respect to cellular composition and histopathological appearance, animal models of EAE are most valuable in studying pathogenetically relevant consequences of defined manipulations. Moreover, such lesions can be studied at any time point, which explains why EAE models also in terms of histopathology are a most precious addition to the repertoire of modern MS research tools.

\section{Use of transgenic mice to unravel pressing questions about the pathogenesis of CNS inflammation; knockout mice}

Specific mouse genes can routinely be overexpressed as transgenes or eliminated by gene targeting ("knockouts"), which allows a "clean" and direct assessment of the causative roles of certain molecules in disease pathogenesis. Various transgene constructs involving targeted expression of $\mathrm{MHC} /$ costimulatory molecules or alterations of the TCR repertoire towards a highly autoreactive population have been designed to challenge the immune system's mechanisms of self-tolerance [66]. Studies in transgenic and knockout mice have implicated a number of effector molecules such as cytokines, chemokines, and other proteins in MS [67]. The conventional approach has several disadvantages; transgene expression may have direct toxic effects on the target tissue and be insensitive to regulatory networks, and in particular, normal developmental kinetics cannot be mimicked, as expression is either "on" or "off" from time of developmental onset (reviewed in [68-71]). Further (conditional) techniques have been developed to limit manipulated gene expression to defined cell types (Cre-loxP system of site-specific recombination [72]) and specific time points. Commonly used examples for such a spatial and temporal control of genes of interest are the 


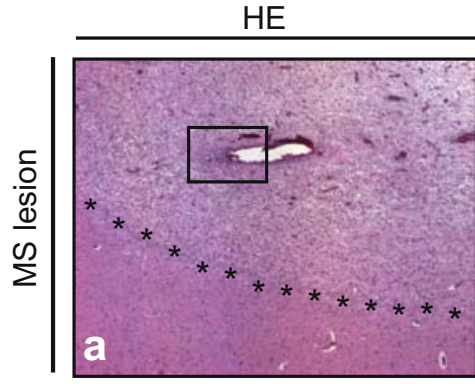

HLA class II
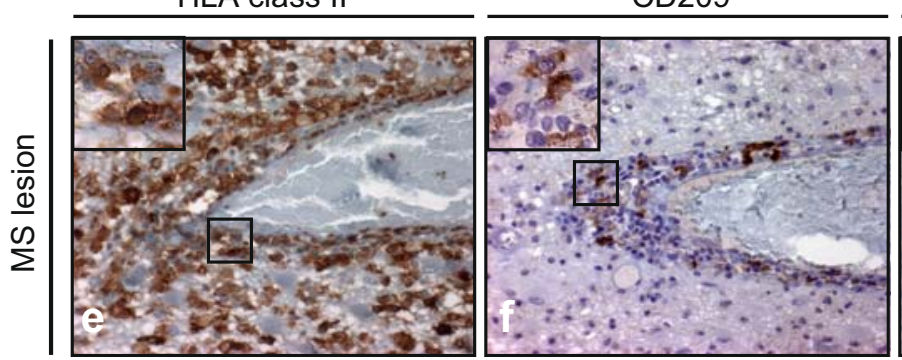
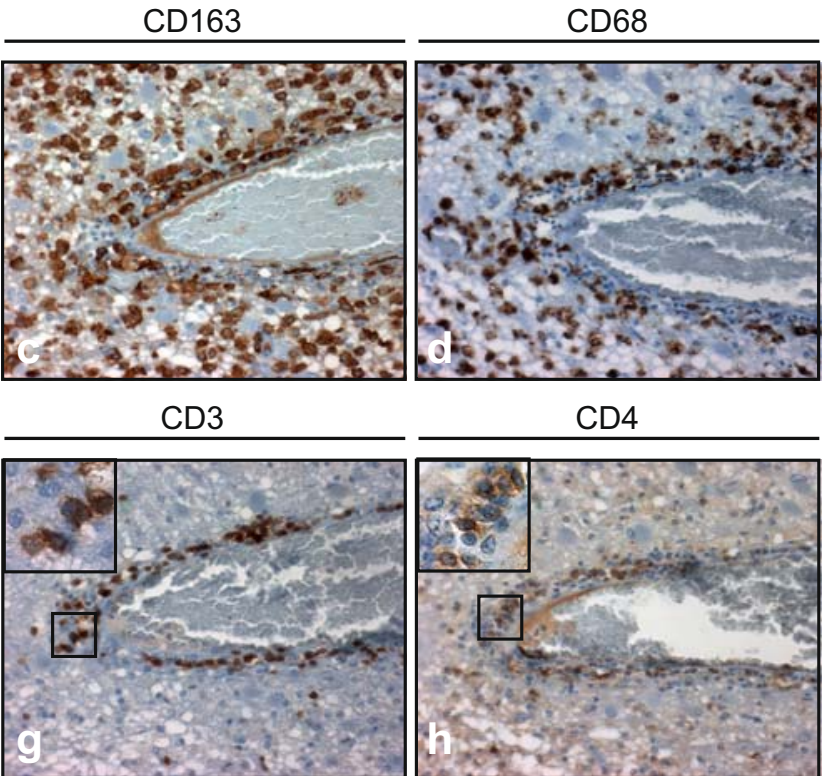

CD4

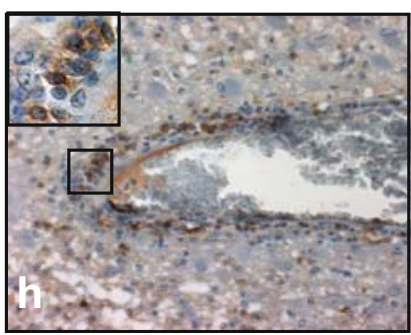

Fig. 1 Histopathology of acute and/or chronic active MS lesion: severe demyelination (H\&E (a); LN, Luxol-Nissl (b)) and numerous CD163+ (c) or $\mathrm{CD}_{68}+$ (d) macrophage and microglia-rich inflammatory infiltrates including prominent perivascular inflammation are predominant histopathological findings. Gray and white matter in $\mathbf{a}$ and $\mathbf{b}$ is separated by asterisks. Rectangles represent the area chosen for higher-magnification analysis throughout. While strong HLA class II immunoreactivity (e) was present throughout the MS lesion, CD209+ cells (f) were mainly restricted to vessels and seen in close proximity to invading CD3+ (g) and CD4+ (h) T cells. Scale bar $400 \mu \mathrm{m}(\mathbf{a}, \mathbf{b})$, $100 \mu \mathrm{m}$ for all other panels. Adapted from [42]

manipulations of cytokine/chemokine expression offer a relatively nonintrusive technique for assessment of their role (reviewed in $[68,76]$ ). In vivo cell lineage ablation, e.g., of $\mathrm{MOG}^{+}$oligodendrocytes, has recently been improved by stable mouse lines, carrying conditional expression constructs for diphtheria toxin (DT) or DT receptor (DTR) that could be activated upon Cre-mediated recombination and the application of DT, respectively [77]. CD11bherpes simplex virus thymidine kinase (HSVTK) transgenic mice, which express HSVTK in macrophages/microglia neuroectodermal cells of the CNS [75]. CNS-targeted

tetracycline-controlled transactivator system [73] and the ( The nestin-Cre transgene mediates excision of loxPflanked sequences in early neuronal precursors during embryonic life, resulting in target gene inactivation in all
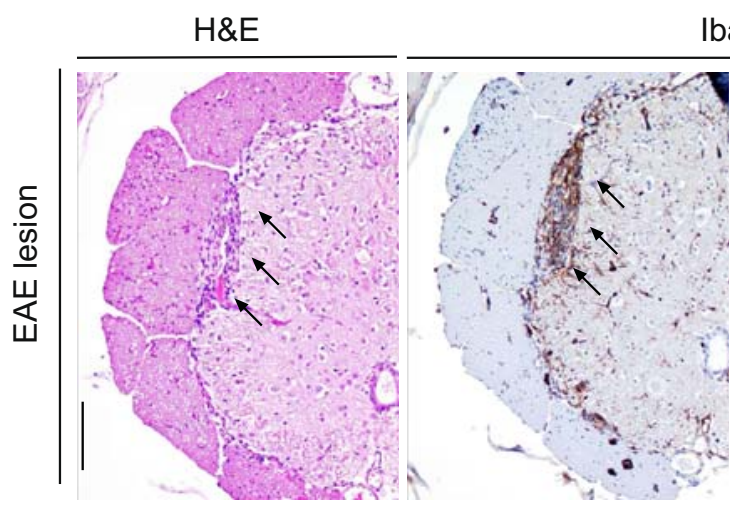

Iba1
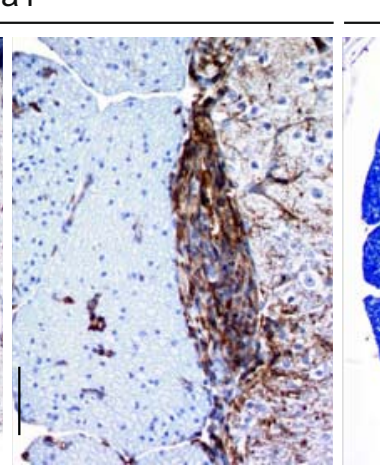

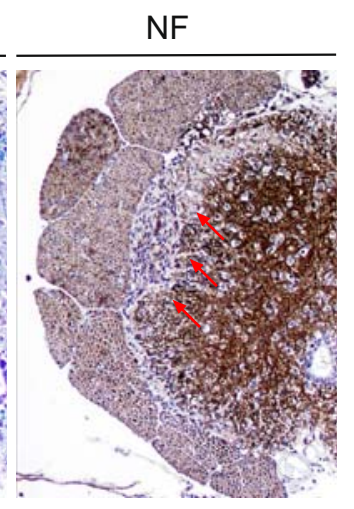

Fig. 2 Spinal cord cross sections of wild-type mice displaying an acute perivascular EAE lesion (H\&E, arrows), mainly consisting of activated Iba1+ macrophages/microglia (second and, at higher magnification, third row). Impairment of myelinated (Luxol-Nissl, $L N$; fourth row) and axonal structures (neurofilament, $N F$, fifth row), while indicated due to the early state is not yet fully developed (and better visible in chronic lesions). Scale bars $100 \mu \mathrm{m}$ for first, third, fourth, and fifth column; $100 \mu \mathrm{m}$ for second, fourth, and sixth column. Adapted from [96] 
have been generated as a tool to study the impact of microglial activation on CNS disease in vivo. Expression of HSVTK renders preferentially proliferating cells sensitive to ganciclovir, as the active metabolite competes with thymine for DNA synthesis [45]. To dissect APC functions in the CNS parenchyma versus the periphery, gene targeting can also be combined with bone marrow chimerism [42]. Astrocyte activation during EAE in vivo was monitored by Luo and colleagues by the use of bioluminescence imaging in mice expressing luciferase under the control of a GFAP promoter [78]. "Knock-ins" of functional cytokine genes have been ligated to green fluorescent protein (GFP) for cell tracking of cytokine-producing cells [79]. Based on the linked expression of GFP to Foxp $3^{+} \mathrm{T}$ cells, two groups have generated Foxp3gfp.KI mice in order to reliably monitor regulatory $\mathrm{T}$ cells (T-reg) in vivo $[80,81]$. Taken together, the true strength of the mouse model is its capacity to intervene with the pathogenesis of inflammatory CNS disease at the molecular level and to prove or mostly dismiss hypothesis about the involvement of specific molecules in the inflammatory cascade.

\section{Cytokines and mediators of inflammation}

Upon cognate antigen recognition on an activated APC, T cells become polarized towards an effector type depending on the quality of priming immune synapse and the cytokines present. Signaling of certain signature cytokines results in lineage commitment towards one of the three effector types, termed $\mathrm{T}_{\mathrm{H}} 1, \mathrm{~T}_{\mathrm{H}} 2$, or $\mathrm{T}_{\mathrm{H}} 17$. The classic paradigm, proposed by Mosmann and Coffman in 1986, strictly divided effector $T_{H}$ cells into $T_{H} 1$ cells, directing cell-mediated immunity, and $\mathrm{T}_{\mathrm{H}} 2$ cells, regulating $\mathrm{B}$ cell activity and humoral immunity [82]. $\mathrm{T}_{\mathrm{H}} 1$ cells produce primarily IFN- $\gamma$ and IL-2, while IL- 4 and IL-5 are produced by $\mathrm{T}_{\mathrm{H}} 2$ cell. Lineage commitment employs autocrine loops for "self-propagation" and reciprocal inhibition via their cytokines. In addition to the $\mathrm{T}_{\mathrm{H}} 1$-promoting effects of IFN- $\gamma$ itself, $\mathrm{T}_{\mathrm{H}} 1$ cells are predominantly polarized by the APC-derived factors IL-12 and IL-18 [83]. The $\mathrm{T}_{\mathrm{H}} 1 / \mathrm{T}_{\mathrm{H}} 2$ paradigm provided a conceptional framework which shaped our understanding of communication pathways during adaptive immune response. Over the years, $\mathrm{T}_{\mathrm{H}} 1$ cells were found to be the main culprits behind CNS inflammation, primarily based on the fact that inflammatory CNS lesions and invading $\mathrm{T}$ cells produced IFN- $\gamma$. In MS patients, elevated levels of IL-12p40 mRNA were detected in the CNS [84], while in the animal model EAE such $T_{H} 1$ cells were shown to actually infiltrate the CNS in great numbers and produce their effector cytokines when CNS inflammation occurred. Purified $\mathrm{T}_{\mathrm{H}} 1$ cells could be transferred into naive animals and mediate autoimmune disease. Conversely, $\mathrm{T}_{\mathrm{H}} 2$ cells were shown to exert beneficial effects in EAE (reviewed in [85]).
Given the overwhelming case for $\mathrm{T}_{\mathrm{H}} 1$ cells and IFN- $\gamma$, it was surprising at first that in mice none of the $T_{H} 1$ and $T_{H} 1$ inducing cytokines (IFN- $\gamma$, IL-12, IL-18, TNF- $\alpha$ ) could account for the proposed importance of the $\mathrm{T}_{\mathrm{H}} 1$ effector cells in the disease [86-89]. Even though functional studies could hardly verify the pivotal role of $\mathrm{T}_{\mathrm{H}} 1$ cells in autoimmunity, the model was not abandoned but clearly dominated common belief for decades. A tangible alternative was proposed with the discovery that the IL-12 family member IL-23 instead of IL-12 itself is a prerequisite for the development of EAE [87, 90, 91]. The central role of IL23 in EAE was proven by Sedgewick and colleagues by the deletion of the p19 subunit of IL-23 [91]. The particular impact connected to this finding was the description of a novel $\mathrm{T}_{\mathrm{H}}$ cell effector type, which showed IL-23-dependent expansion and expression of the proinflammatory cytokine IL-17A [23]. They were therefore coined $\mathrm{T}_{\mathrm{H}} 17$ cells. IL-23- and IL-6-deficient mice showed impaired $\mathrm{T}_{\mathrm{H}} 17$ polarization. In consequence, it seems that such loss rendered the mice resistant to EAE [24]. A plethora of data was generated that correlated $\mathrm{T}_{\mathrm{H}} 17$ cells and IL-17A expression with the development of autoimmune inflammation in mice and humans (reviewed in [92]). Almost forgotten was the fact that in most respects $\mathrm{T}_{\mathrm{H}} 1$ cells and $\mathrm{T}_{\mathrm{H}} 1$ cytokines correlate just as well with autoimmune disease and that adoptive transfer of $\mathrm{T}_{\mathrm{H}} 1$ cells for the passive induction of EAE was the standard procedure for years.

Surprisingly, IL-17A neutralization in EAE in C57BL/6 mice by Hofstetter et al., however, only revealed a very mild effect of treatment with either monoclonal antibodies against IL-17A or with the soluble receptor of IL-17A and F [93]. IL-17A-/- mice were generated by the group of Iwakura and found to be fully susceptible to EAE after active immunization but demonstrate an alleviated course of clinical EAE in the chronic phase of disease [94]. Even more surprisingly, these findings were then interpreted by others to represent the clear and solid proof that IL-17A is the key player in CNS autoimmune inflammation in mice and probably in men as well. The slight change in the course of EAE found upon deletion of IL-17A certainly confirms its proinflammatory properties at the site of an active autoimmune lesion but, nonetheless, fails to mark it as an essential encephalitogenic factor. Haak et al. and Kreymborg et al. have by now dismissed the $\mathrm{T}_{\mathrm{H}} 17$ cytokines IL-17A, IL-17F, and IL-22 as critical players in the EAE pathogenesis $[95,96]$. After an initial confusion in the field, it remains a solid fact that IL-23 is vital for EAE development while $\mathrm{T}_{\mathrm{H}} 17$ cells and their cytokines display a great deal of redundancy. Recently, McGeachy et al. and Gyülvészi et al. reported that IL-23 promotes the CNS tropism of encephalitogenic T cells [97, 98]. The mechanistic underpinnings of this phenomenon remain to be established. 
Hence, while we have clear evidence that a certain quality of $\mathrm{T}$ cell effector function permits encephalitogenic $\mathrm{T}$ cells access into the CNS, the precise molecular signature remains to be established.

\section{BBB biology and leukocyte trafficking to the CNS}

Under physiological conditions, a limited number of leukocytes enter the CNS (referred to as immune surveillance; [99]). In the course of EAE, BBB dysfunction is associated with increased leukocyte extravasation across CNS postcapillary venules and subsequent leukocyte accumulation in the perivascular space forming inflammatory cuffs. In postcapillary venules, the endothelial cell monolayer and underlying basement membrane, ensheathing astrocyte end feet, leptomeningeal cells, and their associated parenchymal basal membrane all contribute to the BBB [100]. Therefore, EAE presents an excellent model to study leukocyte migration across the BBB into the CNS during autoimmune inflammation. Several techniques have been developed to assess the disruption of the BBB in situ, like immunohistochemical analysis for tight junction proteins, serum-derived proteins (fluorescein isothiocyanate albumin leakage assay, [101]), or Evans Blue diffusion [102, 103]. In vivo tracing studies using genetically or fluorescently labeled leukocytes have been combined with intravital microscopic analysis to study interactions with superficial brain microvasculature [104]. Finally, to further elucidate molecular mechanisms of CNS trafficking neutralizing antibodies, small molecule inhibitors or (endothelial specific) transgenic/knockout models of trafficking determinants like adhesion molecules can be used [105].

In EAE, intravital fluorescence videomicroscopy has revealed an integrin $\alpha_{4}$ - and P-selectin-dependent rolling of leukocytes along CNS vessels, without the involvement of E-selectin as in other tissues [106] and an integrin $\alpha_{4} \beta_{1}$ (very late antigen-4, VLA-4)-mediated, G-proteinindependent capture of $\mathrm{T}$ cells at the endothelial cell surface $[104,107]$. The integrin $\alpha_{4} \beta_{1}$ ligand, vascular cell adhesion molecule (VCAM-1), as well as intercellular adhesion molecule 1 (ICAM-1), and activated leukocyte cell adhesion molecule (ALCAM) are well-described adhesion molecules expressed on inflamed BBB endothelial cells and seem to be important for leukocyte transmigration $[108,109]$. The realization that integrin $\alpha_{4} \beta_{1} / \mathrm{VCAM}-1$ interactions play a crucial role in leukocyte adhesion to the BBB has led to the development of natalizumab, a humanized anti- $\alpha_{4}$-integrin antibody, as an effective novel drug for the treatment of MS $[110,111]$. More recent data indicate that $\alpha_{6} \beta_{1}$ integrin, the major receptor of laminin 4 , mediates $\mathrm{T}$ lymphocyte migration across the endothelial basement membrane. Elimination of laminin 4 or $\alpha_{6} \beta_{1}$ integrin resulted in reduced $\mathrm{T}$ cell infiltration and EAE severity [112]. Functional expression of CCL19 and CCL21 occurs in CNS venules surrounded by inflammatory cuffs, and these lymphoid chemokines have been implicated in $\mathrm{T}$ lymphocyte migration across the endothelial cell monolayer [113]. Previous studies have suggested that subsequent migration out of the perivascular cuff and into the CNS parenchyma requires the classical inflammatory chemokines, including CCL2 [114-116]. Further, leukocytes use focal matrix metalloproteinase (MMP-2 and MMP-9) activity to penetrate the parenchymal basement membrane [117].

\section{Models of CD8-mediated EAE}

Attention has long been focused on CD4+ T cells because susceptibility of MS is associated with MHC class II genes [118], and CD4 T cells are critical to the induction in most EAE models [119]. However, CD8+ T cells have also been implicated in MS by their higher number and invasiveness into the parenchyma compared to mainly perivascularly clustered CD4+ T cells in MS lesions [65, 120-122], their clonal expansion based on TCR analysis [123, 124], and their pathogenicity in certain EAE models [22, 125, 126], whereas in other models, CD8 $+\mathrm{T}$ cell may play a regulatory role and protect against the disease development [123, 127-129]. Data showing that CD8+ T cells can, in some conditions, directly attach to and transect axons support the idea that CD8+ T cells mediate damage [130].

\section{CD4 bias after immunization}

Due to the method of induction of classical EAE with CNS-derived antigen emulsified in adjuvants which favors a CD4+ $\mathrm{T}$ cell bias in the population of responding myelin-specific $\mathrm{T}$ cells, EAE is not an ideal model to investigate the contribution of $\mathrm{CD} 8+\mathrm{T}$ cells to disease. The most important component in the adjuvant CFA is heat-inactivated Mycobacterium tuberculosis, which induces a prominent MHC-class-II-restricted $\mathrm{CD} 4+\mathrm{T}_{\mathrm{H}} 1$ response [131, 132].

Myelin-specific CD8 $+\mathrm{T}$ cells can adoptively transfer EAE, thereby establishing a pathogenic role for $\mathrm{CD} 8+\mathrm{T}$ cells in EAE and providing a model for analysis of CD8+ T cells in MS. In a study by Huseby et al., adoptive transfer of MBP-specific CD8+ T cells isolated from wild-type $\mathrm{C} 3 \mathrm{H}$ mice mediated severe CNS autoimmunity [21]. The symptoms resembled many features of MS not seen in CD4+ T-cell-mediated EAE models, such as ataxia, spasticity, hyperreflexiveness, and loss of coordinated movements. CNS demyelinating lesions predominated in the brain versus the spinal cord, which was quite distinct 
from most CD4+ T-cell-mediated models of EAE in which the lesions are mainly found in the spinal cord. Perivascular cuffs were composed of lymphocytes, macrophages, and a few neutrophils. CD8 + T-cell-mediated CNS autoimmunity was independent of CD4+ T cells and largely inhibited by neutralizing IFN- $\gamma$ activity. Two other groups successfully induced CD8+ T-cell-mediated EAE in C57BL/6 mice by transferring $\mathrm{CD} 8+\mathrm{T}$ cells specific for $\mathrm{MOG}_{37-46}$ into syngeneic mice $[22,126]$.

Transgenic models (auto versus neo Ag)

Several transgenic mouse models have been developed to study the pathogenic role of CD8 $+\mathrm{T}$ cells in autoimmune CNS inflammation. Brisebois and colleagues have recently shown that endogenous CD8 $+\mathrm{T}$ cells were necessary for the development of full-blown neuroinflammation in mice overexpressing the costimulatory ligand CD86 on microglia cells [133]. The majority of T cells in the CNS of mouse mutants that overexpress PLP in oligodendrocytes expressed CD8 [134].

Other systems have employed TCR transgenic T cells recognizing natural or model brain autoantigens in an MHC-class-I-restricted manner. In GFAP-hemagglutinin $(\mathrm{HA}) \times$ CL4-TCR double transgenic mice, in which the viral (neoself) antigen influenza $\mathrm{HA}$ is specifically expressed in astrocytes and enteric glia and in which most CD8+ T cells are HA specific, early death due to an attack on enteric glial cells precluded the analysis of EAE development [135]. Adoptive transfer of HA-specific $\mathrm{CD} 8+\mathrm{T}$ cells resulted in immune cell infiltration in the brains of transgenic mice, expressing HA in astrocytes, but failed to induce clinical CNS disease [136]. In H-2Krestricted $\mathrm{MBP}_{79-87}$ TCR transgenic mice, MBP-specific CD8+ T cells sufficed to induce CNS autoimmunity, but immune tolerance prevented these autoreactive cells from causing disease [137]. Transgenic mice expressing a Borna disease virus (BDV) antigen in either neurons or astrocytes were also tolerant to the neoself antigen. In this model, however, adoptive transfer of activated BDVspecific CD8 $+\mathrm{T}$ cells was sufficient to induce disease, which was attributed to the high viral antigen concentrations in the CNS [138].

Mice in which the model antigen influenza HA is selectively expressed in oligodendrocytes have been generated (DKI) to test whether autoreactive CD8+ T cells can contribute to the loss of oligodendrocytes as observed in MS plaques. Crossing these mice to CL4-TCR transgenic mice did not result in spontaneous neuroinflammation, and CL4-TCR transgenic CD8 + T cells rather seemed to remain "indifferent" to the neoself antigen sequestered in the CNS. However, transfer of preactivated HA-specific CD8+ T cells in DKI mice led to inflammatory lesions in the optic nerve, spinal cord, and brain [139]. In another study, intracerebral injection of the influenza virus $\mathrm{HA}_{512-520}$ peptide in soluble form in CL4-TCR transgenic mice initiated CNS infiltration by the circulating HA-specific CD8+ T cells. It was suggested that peptide-loaded MHC class I molecules expressed on the luminal side of endothelial cells at the BBB might have triggered transmigration [140]. A similar model for CNS-specific autoimmunity employed ovalbumin (OVA) sequestered as a neoself antigen in the cytosol of oligodendrocytes. Introduction of the MHC-class-I-restricted, OVA-specific OT-I TCR as a second transgene led to spontaneous fulminant demyelinating EAE with MS-like lesions, affecting cerebellum, brainstem, optic nerve, and spinal cord. Endogenously generated OT-1 TCR transgenic CD8+ $\mathrm{T}$ cells were highly encephalitogenic, which seemed to depend on a BBB, permeable for naïve CD8 $\mathrm{T}$ cells during the first 10 days of life and on the production of IFN- $\gamma$. In contrast, OVA-specific CD4+ T cells (OT-II), remained fully ignorant of the self-antigen unless OT-I TCR Tg CD8+ T cells first released OVA from oligodendrocytes for peripheral presentation [141]. Recently, a role for HLA-A-restricted CD8+ T cells in the pathogenesis of an MS-like disease was also demonstrated in humanized mouse models [142, 143].

\section{Infection-induced CD8 expansion}

CD8+ $\mathrm{T}$ cells are key mediators in the immune response to many viral infections, and a role for $\mathrm{CD} 8+\mathrm{T}$ cells in demyelination has been illustrated in viral models of CNS inflammation. CD8 $+\mathrm{T}$ cells are essential for clearance of virus but might also become pathogenic and damage CNS tissue. Several mechanisms have been described to explain how viruses might trigger autoimmune disease including adjuvant effects and the provision of viral antigens that are similar to self-antigens and stimulate cross-reactive immune responses (molecular mimicry; reviewed in [144]). Models of molecular identity, although artificial, showed that an immune response to a viral infection could recognize identical antigens presented as self in the CNS, resulting in overt CNS autoimmune disease [145, 146]. During lymphocytic choriomeningitis virus (LCMV) infection, LCMV-specific CD8+ T cells expand greatly [147, 148]. Evans and colleagues generated transgenic mice that expressed the nucleoprotein or glycoprotein of LCMV as self in oligodendrocytes. After peripheral (but not CNS) infection with LCMV, the virus was efficiently cleared, but a chronic CNS autoimmune disease developed characterized by $\mathrm{T}$ cell inflammatory lesions with mainly $\mathrm{CD} 8+\mathrm{T}$ cells, areas of focal myelin loss, marked upregulation of MHC class I and II molecules, and clinical motor dysfunction. Autoimmune responses in the CNS developed 
despite the fact that LCMV was not detectable in the CNS, demonstrating that autoimmunity can occur at a site distal to the initiating infection [145]. In other models of molecular identity/mimicry, autoimmune disease is induced by infection with a nonpathological Theiler's murine encephalomyelitis virus (TMEV) variant that was engineered to express the immunodominant self-epitope from myelin PLP peptide ( PLP $\left._{139-151}\right)$ [146] or viral peptides that mimic PLP ${ }_{139-151}$ [149]. Other studies focusing on viral infections of the CNS have revealed that $\mathrm{T}$ cells under certain circumstances are able to bypass recognition of peptide-MHC complexes and mediate tissue destruction without TCR engagement [150, 151]. Haring and colleagues used transgenic TCR/RAG2 ${ }^{-/-}$mice with only $\mathrm{T}$ cells that are not specific for mouse hepatitis virus to show that activated $\mathrm{CD} 8+\mathrm{T}$ cells are able to cause bystander tissue damage even in the absence of cognate antigen in the CNS [150].

\section{Theiler virus and models of demyelination}

TMEV-induced demyelinating disease

TMEV, murine hepatitis virus, and Semliki Forest virus are useful models for understanding the potential viral etiology of MS (reviewed in [152]). Intracerebral infection of susceptible strains of mice, such as SJL, with natural TMEV leads to either rapidly fatal encephalomyelitis (highneurovirulence strains) or persistent CNS infection and immune-mediated demyelination (low-neurovirulence strains, BeAN, or DA; [153, 154]). Gait disturbances, spastic hind limb paralysis, and urinary incontinency start 30-40 days after infection. Intracerebral injection of virus leads to persistent CNS infection. The level of infectious virus is low during the chronic phase, but abundant amounts of viral RNA and antigen can be detected throughout the lifetime of the mouse [155-157]. During the acute phase of the disease, virus replication is mainly in neurons, whereas during the chronic phase, TMEV persists predominantly in macrophages and glia [155, 158-160]. Virus particles have been identified in oligodendrocytes which have a "dying back" pathology [161]. TMEV virus is known to cause demyelination in infected nude mice that cannot generate mature $\mathrm{T}$ lymphocytes [162], also pointing to a direct viral effect on myelin damage.

Upon TMEV infection, a variety of chemokines and cytokines are induced in primary astrocytes via the nuclear factor $\mathrm{\kappa B}$ pathway including TNF- $\alpha$, IL-1, IL-6, CCL2, and CCL5 [163-165]. Inflammatory responses to TMEV infection seem to depend on toll-like receptor (TLR) 3 and TLR2 [166, 167], as well as protein kinase R, signaling
[168]. The immune response is initially directed against persistent viral antigens, but the chronic phase of the disease is dependent on de novo activation of autoimmune CD4+ $\mathrm{T}$ cell responses against CNS myelin that develop locally as a result of the release of myelin antigens, i.e., epitope spreading [26, 169-171]. In SJL mice, reactivity appears to multiple myelin peptides starting with the immunodominant epitope and spreading later to other subdominant myelin determinants in a hierarchical manner $[170,172]$. Resistance to persistent CNS infection by TMEV is controlled by multiple genetic loci, with the strongest linkage to the class I H-2D MHC region [173, 174], which indicates a role for $\mathrm{CD} 8+\mathrm{T}$ cells. Most evidence points towards a protective function of $\mathrm{CD} 8+\mathrm{T}$ cells via the clearance of TMEV from the CNS [175-178]; however, there is also evidence that MHC-class-I-restricted CD8+ T might be directly cytotoxic to axons and mediate injury $[179,180]$.

Cuprizone and lysolecithin, demyelination without autoimmunity

Several toxin-based models of demyelination, including cuprizone and lysolecithin, while not attempting to accurately mimic the pathogenesis of autoimmune CNS inflammation, have proven very useful to study the mechanisms of demyelination and remyelination. In contrast to the systemically administered cuprizone, the membranesolubilizing, glia-toxic lysolecithin has been used to create focal areas of demyelination by direct injection into defined CNS white matter tracts, which allows for a better control of lesion size and location (reviewed in [181]).

Feeding of cuprizone (bis(cyclohexanone)-oxaldihydrazone) to young adult mice induces a consistent, synchronous, and anatomically reproducible demyelination. Furthermore, removal of cuprizone of the diet of mice leads to remyelination (reviewed in [182]). Cuprizone is a chelator that binds copper, an essential component of metalloenzymes, like the mitochondrial cytochrome oxidase and monoamine oxidase. It has been assumed although not proven that copper deficiency results in specific damage to oligodendrocytes in the CNS and subsequent demyelination. The specific susceptibility of oligodendrocytes has been attributed to the high metabolic demand of these glial cells required to maintain a vast expanse of myelin and the resulting vulnerability to a disturbed energy metabolism.

Genetic factors and gender influence susceptibility to cuprizone-induced demyelination [183]. Cuprizone can induce demyelination in different strains of mice, among them in $8-10$-week-old C57BL/6 mice, the background most commonly used for knockout and transgenic mice. A $0.2 \%$ dose of cuprizone is usually well tolerated. If 
cuprizone is overdosed, (mitochondrial) hepatopathy and weight loss are serious toxic effects [184]. The regional pattern of demyelination includes white matter tracts preferentially the corpus callosum, as well as the cerebellar peduncles [185]. More recently, cortical demyelination has been detected [186], and demyelination in the hippocampal formation has been associated with seizures in the cuprizone model [187, 188]. Substantial demyelination is present starting after 3 weeks of cuprizone, and by $4-5$ weeks more than $90 \%$ of axons will be demyelinated. Under continued exposure of cuprizone, about $50 \%$ of axons recover and are remyelinated by 6 weeks. If cuprizone is discontinued by this time, recovery continues, so that by 10 weeks $90 \%$ of the axons are remyelinated. If, in contrast, the cuprizone challenge is retained, demyelination again dominates so that few myelinated fibers remain [182]. During cuprizone toxicity, there is also demyelination-associated axonal loss which is more prominent in aged mice [189]. Reduction in average axon caliber and some dystrophic neurites are observed [190, 191]. Demyelination/remyelination is preferentially quantitated by ultrastructural analysis performed by electron microscopy, which is best to evaluate the number of myelinated axons, thickness of the myelin sheath, and relationship to the axon size. Histochemical lipid staining with Luxol Fast Blue-periodic Schiff or immunostaining for myelin proteins allows us to estimate and screen for myelination semiquantitatively. Biochemical (lipid) assays analyze the content of the myelin sheath [192]. Magnetic resonance imaging (MRI) has been used to map the pattern of demyelination noninvasively [193]. During administration of cuprizone, the expression of myelin genes in the brain decreases, and most of the mature oligodendrocytes in the corpus callosum, the site of particular profound demyelination, undergo apoptosis [194]. Studies of changes in oligodendrocyte precursor and mature oligodendrocyte dynamics suggest that oligodendrocyte precursors drive the repopulation of oligodendrocytes in the remyelination phase [194]. Oligodendrocyte precursor cells are detectable in the corpus callosum, presumably proliferate, and convert to mature glutathione S-transferase (GST)- $\Pi^{+}$oligodendrocytes during remyelination [194], sequentially expressing myelin proteins [195].

In contrast to EAE, the $\mathrm{BBB}$ seems to remain intact [196, 197]; T cells are almost completely absent, and microglia/macrophages accumulate and predominate in the demyelinated areas [198, 199]. Bone marrow studies indicate that resident microglia outnumbers peripheral macrophages that are recruited in cuprizone-induced CNS demyelination [197]. Studies using lymphocyte-deficient RAG-1 mice have demonstrated that lymphocytes may not play a role in the cuprizone model [200, 201]. Microglia/ macrophages are the main cell type responsible for clearance of myelin debris and are able to secrete a wide variety of cytokines. Analysis of MHC-II-null mice showed reduced inflammation, delayed remyelination, and regeneration of oligodendrocytes, whereas removal of MHC I had little effect [201, 202]. Macrophage depletion by treatment with clodronate liposomes throughout the remyelination phase significantly decreases the extent of oligodendrocyte remyelination following lysolecithin-induced demyelination [203]. Various inflammatory products, including IFN- $\gamma$, IFN- $\beta$, leukemia inhibitory factor, lymphotoxin- $\alpha$, lymphotoxin- $\beta$, IL- $1 \beta$, nitric oxide, insulin-like growth factor, and macrophage inflammatory protein $1 \alpha$, have been studied in the cuprizone model and have been shown to have a deleterious or protective role [204-214]. TNF- $\alpha$ seems to be protective, promoting proliferation, differentiation of oligodendrocyte progenitors (bromodeoxyuridinelabeled $\mathrm{NG}^{+}$cells), and subsequent remyelination [200]. Thus, induction of MHC II by TNF- $\alpha$ has been suggested as an important regulatory event in remyelination, emphasizing the active inflammatory response in brain regeneration after brain injury [202].

Neuropathological changes observed during cuprizone treatment correlate with alterations in the neurological function such as hyperactive behavior and mild motor dysfunction detectable by sensitive motor tests [215, 216].

Model of lipopolysaccharide-induced demyelination

A number of studies have examined the effects of lipopolysaccharide (LPS) injections into the CNS [217220]. Typically, a local inflammatory reaction is evoked but substantially muted when compared with similar injections in other tissues [217]. Felts et al. described an inflammatory reaction and after a delay of 5-7 days a demyelinating lesion that arise following the injection of LPS into rat spinal white matter [219, 220] and that persist between 9 and 14 days. Besides activation of resident microglia, CNSinfiltrating phagocytes (neutrophils and monocytes) seem to contribute to the inflammatory response [221], although injecting LPS or leukocyte chemotaxis into the CNS seems to induce a lower myelomonocytic recruitment compared to other tissues [217, 222]. Microglial TLR4 is required for leukocyte recruitment into the brain in response to LPS [223]. The exact mechanism of LPS-induced demyelination is unknown. In primary mixed glial cultures, LPS induces a selective loss of oligodendrocyte precursors, and activation of microglia, but not astrocytes, is required for LPS toxicity [224, 225]. Conditioned media from LPS-exposed microglia (or astrocytes) injures oligodendrocyte progenitors [226]. TLR4 is necessary for LPS-induced oligodendrocyte injury in the CNS, although mRNA for the LPS receptors TLR4/CD14 is either absent or only found at very low levels 
in oligodendrocyte precursors [224]. Thus, LPS might not be directly toxic to oligodendrocytes but cause demyelination via factors derived from activated microglia/macrophages (or astrocytes). Accordingly, recent evidence suggests that micro- glial peroxynitrite (the reaction product of nitric oxide and superoxide anion), or in the presence of astrocytes activation of TNF/TNFR signaling, play a key role in LPS-induced damage of developing oligodendrocyte in vitro [225, 227].

\section{MOGi-cre/iDTR}

+DTA
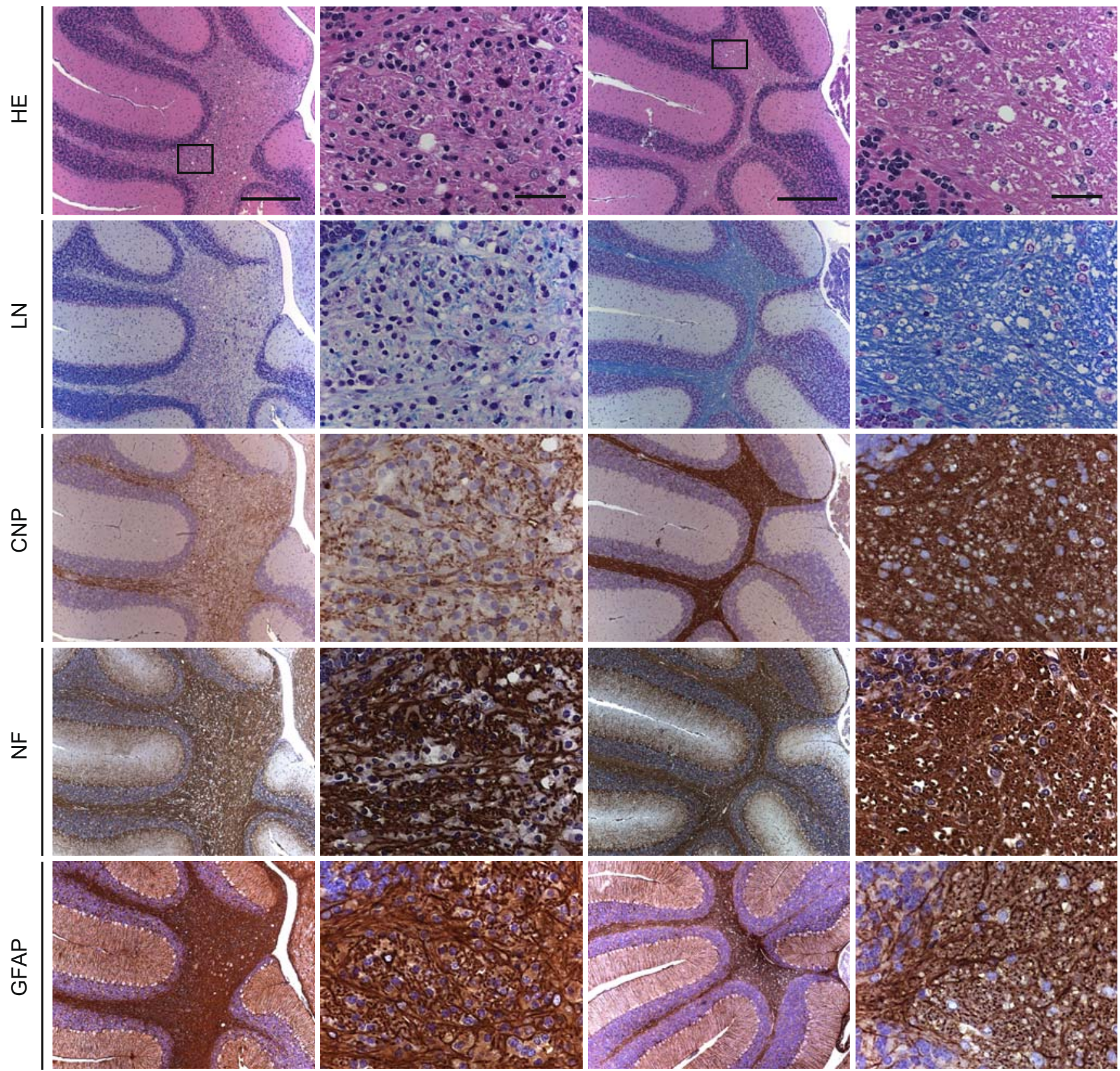

Fig. 3 DT-mediated ablation of oligodendrocytes in MOGi-Cre/iDTR mice: cerebella of DT-treated (+DT, first and second column) MOGiCre/iDTR mice present with a severe destruction of myelinated structures, as visualized by Luxol-Nissl $(L N)$ and CNPase stains. Untreated (-DT) iMOG-Cre/iDTR mice (second and third column) were unaffected. Axonal integrity was affected in DT-treated iMOG-

Cre/iDTR mice (neurofilament immunohistochemistry) and some inflammatory cells (HE) and a mild reactive astrogliosis (GFAP) were visible in DT-treated iMOG-Cre/iDTR mice. Rectangles indicate the adjacent high-magnification image. Scale bar $500 \mu \mathrm{m}$ for first and third column; $100 \mu \mathrm{m}$ for second and fourth column. Adapted from [77] 
Fig. 4 Induction and effector stage of MS/murine models. Abbreviations: EAE, experimental autoimmune encephalomyelitis; $A T$, adoptive transfer; TMEV-IDD, Theiler's murine encephalomyelitis virus-induced demyelinating disease; TCR, T cell receptor; $T g$, transgenic; $K I$, knock-in, $K O$, knockout; $T_{H}$, T helper cell; $B B B$, blood-brain barrier; $M O G$, myelin oligodendrocyte glycoprotein; $M H C$, major histocompatibility complex

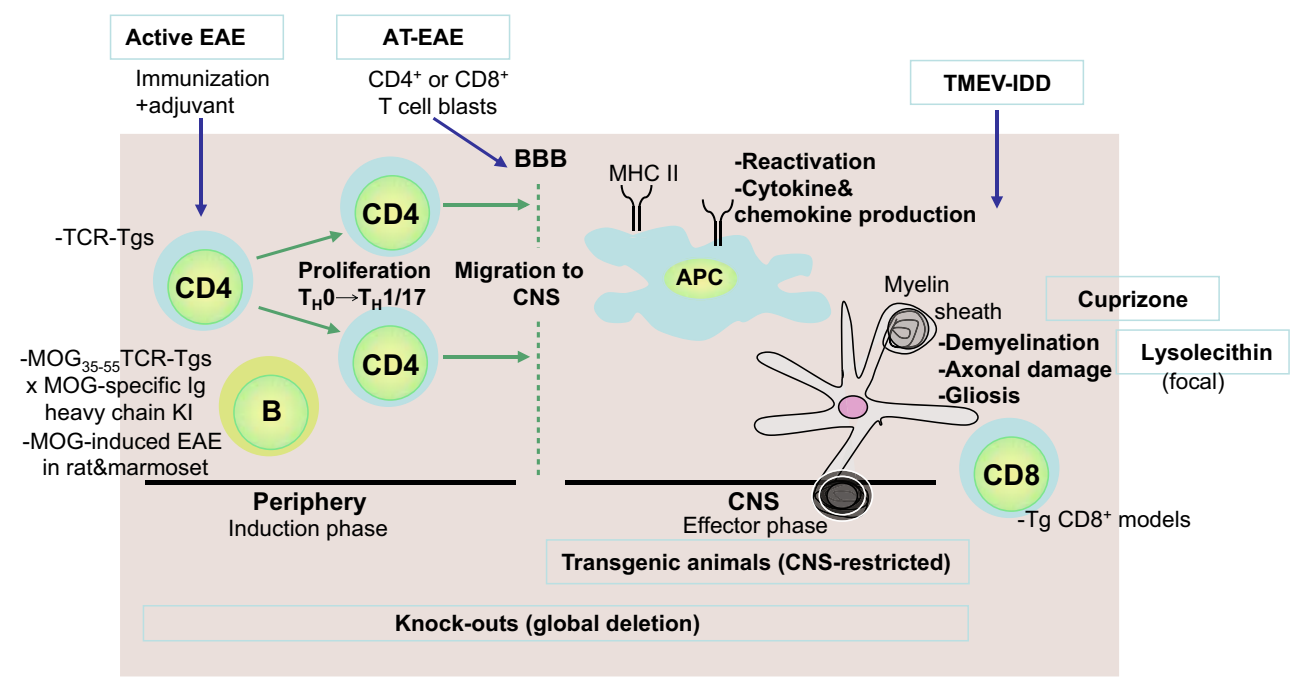

oDTR mice

The means for specific in vivo cell lineage ablation have recently been improved by stable mouse lines, carrying conditional expression constructs for DT or DTR that could be activated upon Cre-mediated recombination and the application of DT, respectively [77, 228]. In Cre-inducible DTR transgenic mice (iDTR) Cre-mediated excision of a STOP cassette renders cells sensitive to DT. DT crosses the $\mathrm{BBB}$ and promotes cell ablation in the CNS. Injecting DT intraperitoneally into MOGi-Cre/iDTR double transgenic mice expressing Cre recombinase under the control of the oligodendrocyte-specific promoter MOG results in a severe myelin loss throughout the CNS [77]. Axonal integrity subsequently also appears to be affected, and some reactive astrogliosis as well as inflammatory cells are seen (Fig. 3). After approximately 30 days, the DT-treated MOGi-Cre/ iDTR mice present clinically with tremor, hind limb paralysis, and weight loss (Fig. 4; Table 1).

\section{Concluding remarks}

Taken together, there is now a plethora of different animal models available, each of them serving the purpose to study specific aspects of the pathogenesis of MS in rodents. Whereas these models are most useful and have provided a wealth of knowledge otherwise unavailable to us, there are a number of limitations in regards to interpreting the data. A number of questions cannot be directly answered in animal models including the initial trigger of the MS pathogenesis (vaccination with autoantigen is hardly to blame), the driving self-Ag, the genetic predisposition, and others. Therefore, none of the described animal models can truly serve for drug testing or replace clinical trials. To this day, the animal models described here are the state-of-theart and the very best modeling system available to us. We need to be cautious not to overinterpret the findings and to continue to create better models to accurately study certain aspects of the pathogenesis of neuroinflammatory disease.

Table 1 Commonly used MS models

\begin{tabular}{|c|c|c|c|}
\hline Model & Mode of induction & Pathomechanism & Phenotype \\
\hline \multirow[t]{6}{*}{ EAE } & -Immunization & $\mathrm{CD}^{+}{ }^{+}$T-cell-mediated & Myelitis (>cerebellitis) \\
\hline & -Adoptive transfer $\left(\mathrm{CD}^{+}\right)$ & " & ” \\
\hline & $\begin{array}{l}\text {-Spontaneous } \rightarrow \text { (humanized) TCR } \\
\text { Tgs (MHCII-restricted) }\end{array}$ & 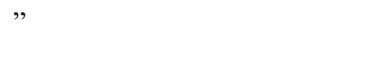 & \\
\hline & -2D2 $\mathrm{MOG}_{35-55} \mathrm{TCR}$ Tgs & " & Optic neuritis [33] \\
\hline & × MOG-specific IgH KI & $\mathrm{CD}^{+}{ }^{+} \mathrm{T} / \mathrm{B}-$ cell-mediated & Devic-like disease [34] \\
\hline & $\begin{array}{l}\text {-In rats/marmosets }(\mathrm{MOG}) \\
\quad \text { [in (conditional) } \mathrm{Tg} / \mathrm{KO} \text { mice }]\end{array}$ & $\mathrm{T}$ cell/antibody-mediated & Encephalomyelitis \\
\hline \multirow[t]{2}{*}{$\mathrm{CD}^{+} \mathrm{AT}$} & -Adoptive transfer $\left(\mathrm{CD}^{+}\right)$ & $\mathrm{CD}^{+}$T-cell-mediated & Brain $>$spinal cord $[21]$ \\
\hline & $\begin{array}{l}\text {-TCR Tgs (MHCI-restricted) } \\
\quad \times \text { auto/neo brain ag [spontaneous] }\end{array}$ & $"$ & Encephalomyelitis \\
\hline TMEV-IDD & -Intracerebral infection & Virus-induced demyelination & Encephalomyelitis \\
\hline Cuprizone & -Feeding & Toxin-based demyelination & $\begin{array}{l}\text { Corpus callosum, cerebellar } \\
\text { peduncles [185] }\end{array}$ \\
\hline Lysolecithin & -Local CNS injection & $"$ & Focal white matter lesion \\
\hline
\end{tabular}




\section{References}

1. Olitsky PK, Yager RH (1949) Experimental disseminated encephalomyelitis in white mice. J Exp Med 90:213-224

2. Brown AM, McFarlin DE (1981) Relapsing experimental allergic encephalomyelitis in the SJL/J mouse. Lab Invest 45:278-284

3. Fritz RB, Chou CH, McFarlin DE (1983) Induction of experimental allergic encephalomyelitis in PL/J and (SJL/J x PL/J)F1 mice by myelin basic protein and its peptides: localization of a second encephalitogenic determinant. J Immunol 130:191-194

4. Trotter JL, Clark HB, Collins KG, Wegeschiede CL, Scarpellini JD (1987) Myelin proteolipid protein induces demyelinating disease in mice. J Neurol Sci 79:173-188

5. Linthicum DS, Frelinger JA (1982) Acute autoimmune encephalomyelitis in mice. II. Susceptibility is controlled by the combination of H-2 and histamine sensitization genes. J Exp Med 156:31-40

6. Kerfoot SM et al (2004) TLR4 contributes to disease-inducing mechanisms resulting in central nervous system autoimmune disease. J Immunol 173:7070-7077

7. Kamradt T, Soloway PD, Perkins DL, Gefter ML (1991) Pertussis toxin prevents the induction of peripheral T cell anergy and enhances the $\mathrm{T}$ cell response to an encephalitogenic peptide of myelin basic protein. J Immunol 147:3296-3302

8. Waldner H, Collins M, Kuchroo VK (2004) Activation of antigen-presenting cells by microbial products breaks self tolerance and induces autoimmune disease. $\mathrm{J}$ Clin Invest 113:990-997

9. Shive CL, Hofstetter H, Arredondo L, Shaw C, Forsthuber TG (2000) The enhanced antigen-specific production of cytokines induced by pertussis toxin is due to clonal expansion of $\mathrm{T}$ cells and not to altered effector functions of long-term memory cells. Eur J Immunol 30:2422-2431

10. Muller DM, Pender MP, Greer JM (2000) A neuropathological analysis of experimental autoimmune encephalomyelitis with predominant brain stem and cerebellar involvement and differences between active and passive induction. Acta Neuropathol 100:174-182

11. Abromson-Leeman S et al (2004) T-cell properties determine disease site, clinical presentation, and cellular pathology of experimental autoimmune encephalomyelitis. Am J Pathol 165:1519-1533

12. Teuscher $\mathrm{C}$ et al (2004) Gender, age, and season at immunization uniquely influence the genetic control of susceptibility to histopathological lesions and clinical signs of experimental allergic encephalomyelitis: implications for the genetics of multiple sclerosis. Am J Pathol 165:1593-1602

13. Smith ME, Eller NL, McFarland HF, Racke MK, Raine CS (1999) Age dependence of clinical and pathological manifestations of autoimmune demyelination. Implications for multiple sclerosis. Am J Pathol 155:1147-1161

14. Fillmore PD et al (2003) Genetic analysis of the influence of neuroantigen-complete Freund's adjuvant emulsion structures on the sexual dimorphism and susceptibility to experimental allergic encephalomyelitis. Am J Pathol 163:1623-1632

15. Maatta JA, Nygardas PT, Hinkkanen AE (2000) Enhancement of experimental autoimmune encephalomyelitis severity by ultrasound emulsification of antigen/adjuvant in distinct strains of mice. Scand J Immunol 51:87-90

16. Oliver AR, Lyon GM, Ruddle NH (2003) Rat and human myelin oligodendrocyte glycoproteins induce experimental autoimmune encephalomyelitis by different mechanisms in C57BL/6 mice. J Immunol 171:462-468

17. Sobel RA (2000) Genetic and epigenetic influence on EAE phenotypes induced with different encephalitogenic peptides. J Neuroimmunol 108:45-52
18. Tsunoda I, Kuang LQ, Theil DJ, Fujinami RS (2000) Antibody association with a novel model for primary progressive multiple sclerosis: induction of relapsing-remitting and progressive forms of EAE in H2s mouse strains. Brain Pathol 10:402-418

19. Pettinelli CB, McFarlin DE (1981) Adoptive transfer of experimental allergic encephalomyelitis in SJL/J mice after in vitro activation of lymph node cells by myelin basic protein: requirement for Lyt 1+ 2- T lymphocytes. J Immunol 127:1420-1423

20. Zamvil S et al (1985) T-cell clones specific for myelin basic protein induce chronic relapsing paralysis and demyelination. Nature 317:355-358

21. Huseby ES et al (2001) A pathogenic role for myelin-specific CD8(+) $\mathrm{T}$ cells in a model for multiple sclerosis. J Exp Med 194:669-676

22. Sun D et al (2001) Myelin antigen-specific CD8+ T cells are encephalitogenic and produce severe disease in C57BL/6 mice. J Immunol 166:7579-7587

23. Langrish CL et al (2005) IL-23 drives a pathogenic $T$ cell population that induces autoimmune inflammation. J Exp Med 201:233-240

24. Stromnes IM, Cerretti LM, Liggitt D, Harris RA, Goverman JM (2008) Differential regulation of central nervous system autoimmunity by $\mathrm{T}(\mathrm{H}) 1$ and $\mathrm{T}(\mathrm{H}) 17$ cells. Nat Med 14:337-342

25. Flugel A et al (2001) Migratory activity and functional changes of green fluorescent effector cells before and during experimental autoimmune encephalomyelitis. Immunity 14:547-560

26. McMahon EJ, Bailey SL, Castenada CV, Waldner H, Miller SD (2005) Epitope spreading initiates in the CNS in two mouse models of multiple sclerosis. Nat Med 11:335-339

27. Lafaille JJ, Nagashima K, Katsuki M, Tonegawa S (1994) High incidence of spontaneous autoimmune encephalomyelitis in immunodeficient anti-myelin basic protein $\mathrm{T}$ cell receptor transgenic mice. Cell 78:399-408

28. Olivares-Villagomez D, Wang Y, Lafaille JJ (1998) Regulatory $\mathrm{CD} 4(+) \mathrm{T}$ cells expressing endogenous $\mathrm{T}$ cell receptor chains protect myelin basic protein-specific transgenic mice from spontaneous autoimmune encephalomyelitis. J Exp Med 188:1883-1894

29. Madsen LS et al (1999) A humanized model for multiple sclerosis using HLA-DR2 and a human T-cell receptor. Nat Genet 23:343-347

30. Ellmerich $\mathrm{S}$ et al (2005) High incidence of spontaneous disease in an HLA-DR15 and TCR transgenic multiple sclerosis model. J Immunol 174:1938-1946

31. Quandt JA et al (2004) Unique clinical and pathological features in HLA-DRB1*0401-restricted MBP 111-129-specific humanized TCR transgenic mice. J Exp Med 200:223-234

32. Waldner H, Whitters MJ, Sobel RA, Collins M, Kuchroo VK (2000) Fulminant spontaneous autoimmunity of the central nervous system in mice transgenic for the myelin proteolipid protein-specific T cell receptor. Proc Natl Acad Sci U S A 97:34123417

33. Bettelli E et al (2003) Myelin oligodendrocyte glycoproteinspecific $\mathrm{T}$ cell receptor transgenic mice develop spontaneous autoimmune optic neuritis. J Exp Med 197:1073-1081

34. Bettelli E, Baeten D, Jager A, Sobel RA, Kuchroo VK (2006) Myelin oligodendrocyte glycoprotein-specific $\mathrm{T}$ and $\mathrm{B}$ cells cooperate to induce a Devic-like disease in mice. J Clin Invest 116:2393-2402

35. Krishnamoorthy G, Lassmann H, Wekerle H, Holz A (2006) Spontaneous opticospinal encephalomyelitis in a doubletransgenic mouse model of autoimmune $\mathrm{T}$ cell/B cell cooperation. J Clin Invest 116:2385-2392

36. Waldor MK et al (1985) Reversal of experimental allergic encephalomyelitis with monoclonal antibody to a T-cell subset marker. Science 227:415-417 
37. Sriram S, Steinman L (1983) Anti I-A antibody suppresses active encephalomyelitis: treatment model for diseases linked to IR genes. J Exp Med 158:1362-1367

38. Jameson BA, McDonnell JM, Marini JC, Korngold R (1994) A rationally designed $\mathrm{CD} 4$ analogue inhibits experimental allergic encephalomyelitis. Nature 368:744-746

39. Seamons A, Perchellet A, Goverman J (2003) Immune tolerance to myelin proteins. Immunol Res 28:201-221

40. Tompkins SM et al (2002) De novo central nervous system processing of myelin antigen is required for the initiation of experimental autoimmune encephalomyelitis. J Immunol 168:41734183

41. Hickey WF, Kimura H (1988) Perivascular microglial cells of the CNS are bone marrow-derived and present antigen in vivo. Science 239:290-292

42. Greter M et al (2005) Dendritic cells permit immune invasion of the CNS in an animal model of multiple sclerosis. Nat Med 11:328-334

43. Becher B, Bechmann I, Greter M (2006) Antigen presentation in autoimmunity and CNS inflammation: how $\mathrm{T}$ lymphocytes recognize the brain. J Mol Med 84:532-543

44. Becher B, Prat A, Antel JP (2000) Brain-immune connection: immuno-regulatory properties of CNS-resident cells. Glia 29:293-304

45. Heppner FL et al (2005) Experimental autoimmune encephalomyelitis repressed by microglial paralysis. Nat Med $11: 146-152$

46. Becher B, Durell BG, Miga AV, Hickey WF, Noelle RJ (2001) The clinical course of experimental autoimmune encephalomyelitis and inflammation is controlled by the expression of CD40 within the central nervous system. J Exp Med 193:967-974

47. Becher B, Durell BG, Noelle RJ (2003) IL-23 produced by CNSresident cells controls $\mathrm{T}$ cell encephalitogenicity during the effector phase of experimental autoimmune encephalomyelitis. J Clin Invest 112:1186-1191

48. Prinz $M$ et al (2006) Innate immunity mediated by TLR9 modulates pathogenicity in an animal model of multiple sclerosis. J Clin Invest 116:456-464

49. De Keyser J, Zeinstra E, Frohman E (2003) Are astrocytes central players in the pathophysiology of multiple sclerosis? Arch Neurol 60:132-136

50. Ridet JL, Malhotra SK, Privat A, Gage FH (1997) Reactive astrocytes: cellular and molecular cues to biological function. Trends Neurosci 20:570-577

51. Volterra A, Meldolesi J (2005) Astrocytes, from brain glue to communication elements: the revolution continues. Nat Rev Neurosci 6:626-640

52. Bailey SL, Schreiner B, McMahon EJ, Miller SD (2007) CNS myeloid DCs presenting endogenous myelin peptides 'preferentially' polarize $\mathrm{CD} 4+\mathrm{T}(\mathrm{H})-17$ cells in relapsing EAE. Nat Immunol 8:172-180

53. McRae BL, Vanderlugt CL, Dal Canto MC, Miller SD (1995) Functional evidence for epitope spreading in the relapsing pathology of experimental autoimmune encephalomyelitis. J Exp Med 182:75-85

54. Vanderlugt CL et al (2000) Pathologic role and temporal appearance of newly emerging autoepitopes in relapsing experimental autoimmune encephalomyelitis. J Immunol 164:670-678

55. Waksman BH, Adams RD (1956) A comparative study of experimental allergic neuritis in the rabbit, guinea pig, and mouse. J Neuropathol Exp Neurol 15:293-334

56. Waksman BH (1960) The distribution of experimental autoallergic lesions. Its relation to the distribution of small veins. Am J Pathol 37:673-693

57. Lebar R, Boutry JM, Vincent C, Robineaux R, Voisin GA (1976) Studies on autoimmune encephalomyelitis in the guinea pig. II.
An in vitro investigation on the nature, properties, and specificity of the serum-demyelinating factor. J Immunol 116:1439-1446

58. Genain CP et al (1995) Antibody facilitation of multiple sclerosis-like lesions in a nonhuman primate. J Clin Invest 96:2966-2974

59. Schluesener HJ, Sobel RA, Linington C, Weiner HL (1987) A monoclonal antibody against a myelin oligodendrocyte glycoprotein induces relapses and demyelination in central nervous system autoimmune disease. J Immunol 139:4016-4021

60. t Hart BA et al (2004) Modelling of multiple sclerosis: lessons learned in a non-human primate. Lancet Neurol 3:588-597

61. Genain CP et al (1994) In healthy primates, circulating autoreactive T cells mediate autoimmune disease. J Clin Invest 94:1339-1345

62. Baxter AG (2007) The origin and application of experimental autoimmune encephalomyelitis. Nat Rev Immunol 7:904-912

63. Bruck W, Kuhlmann T, Stadelmann C (2003) Remyelination in multiple sclerosis. J Neurol Sci 206:181-185

64. Lucchinetti C et al (2000) Heterogeneity of multiple sclerosis lesions: implications for the pathogenesis of demyelination. Ann Neurol 47:707-717

65. Kuhlmann T, Lassmann H, Bruck W (2008) Diagnosis of inflammatory demyelination in biopsy specimens: a practical approach. Acta Neuropathol 115:275-287

66. Miller SD, Karpus WJ (2007) Experimental autoimmune encephalomyelitis in the mouse. Curr Protoc Immunol 15:15.1

67. Brodmerkel CM, Vaddi K (2003) Transgenic animals in inflammatory disease models. Curr Opin Biotechnol 14:652-658

68. Owens T, Wekerle H, Antel J (2001) Genetic models for CNS inflammation. Nat Med 7:161-166

69. Morel L (2004) Mouse models of human autoimmune diseases: essential tools that require the proper controls. PLoS Biol 2:E241

70. Leiter EH (2002) Mice with targeted gene disruptions or gene insertions for diabetes research: problems, pitfalls, and potential solutions. Diabetologia 45:296-308

71. Steinman L (1997) Some misconceptions about understanding autoimmunity through experiments with knockouts. J Exp Med 185:2039-2041

72. Yu Y, Bradley A (2001) Engineering chromosomal rearrangements in mice. Nat Rev Genet 2:780-790

73. Thomas MK et al (2001) Development of diabetes mellitus in aging transgenic mice following suppression of pancreatic homeoprotein IDX-1. J Clin Invest 108:319-329

74. Hirrlinger PG, Scheller A, Braun C, Hirrlinger J, Kirchhoff F (2006) Temporal control of gene recombination in astrocytes by transgenic expression of the tamoxifen-inducible DNA recombinase variant CreERT2. Glia 54:11-20

75. Tronche F et al (1999) Disruption of the glucocorticoid receptor gene in the nervous system results in reduced anxiety. Nat Genet 23:99-103

76. Krishnamoorthy G, Holz A, Wekerle H (2007) Experimental models of spontaneous autoimmune disease in the central nervous system. J Mol Med 85:1161-1173

77. Buch $\mathrm{T}$ et al (2005) A Cre-inducible diphtheria toxin receptor mediates cell lineage ablation after toxin administration. Nat Methods 2:419-426

78. Luo $\mathrm{J}$ et al (2007) Glia-dependent TGF-beta signaling, acting independently of the TH17 pathway, is critical for initiation of murine autoimmune encephalomyelitis. J Clin Invest 117:3306-3315

79. Mohrs M, Shinkai K, Mohrs K, Locksley RM (2001) Analysis of type 2 immunity in vivo with a bicistronic IL-4 reporter. Immunity 15:303-311

80. Bettelli E et al (2006) Reciprocal developmental pathways for the generation of pathogenic effector $\mathrm{TH} 17$ and regulatory $\mathrm{T}$ cells. Nature 441:235-238

81. Fontenot JD et al (2005) Regulatory T cell lineage specification by the forkhead transcription factor foxp3. Immunity 22:329 341 
82. Mosmann TR, Cherwinski H, Bond MW, Giedlin MA, Coffman RL (1986) Two types of murine helper T cell clone. I. Definition according to profiles of lymphokine activities and secreted proteins. J Immunol 136:2348-2357

83. Gutcher I, Becher B (2007) APC-derived cytokines and T cell polarization in autoimmune inflammation. J Clin Invest 117:11191127

84. Comabella M et al (1998) Elevated interleukin-12 in progressive multiple sclerosis correlates with disease activity and is normalized by pulse cyclophosphamide therapy. J Clin Invest 102:671-678

85. O'Garra A, Steinman L, Gijbels K (1997) CD4+ T-cell subsets in autoimmunity. Curr Opin Immunol 9:872-883

86. Willenborg DO, Fordham S, Bernard CC, Cowden WB, Ramshaw IA (1996) IFN-gamma plays a critical down-regulatory role in the induction and effector phase of myelin oligodendrocyte glycoprotein-induced autoimmune encephalomyelitis. J Immunol 157:3223-3227

87. Becher B, Durell BG, Noelle RJ (2002) Experimental autoimmune encephalitis and inflammation in the absence of interleukin-12. J Clin Invest 110:493-497

88. Gutcher I, Urich E, Wolter K, Prinz M, Becher B (2006) Interleukin 18-independent engagement of interleukin 18 receptor-alpha is required for autoimmune inflammation. Nat Immunol 7:946-953

89. Frei K et al (1997) Tumor necrosis factor alpha and lymphotoxin alpha are not required for induction of acute experimental autoimmune encephalomyelitis. J Exp Med 185:2177-2182

90. Gran B et al (2002) IL-12p35-deficient mice are susceptible to experimental autoimmune encephalomyelitis: evidence for redundancy in the IL-12 system in the induction of central nervous system autoimmune demyelination. J Immunol 169:7104-7110

91. Cua DJ et al (2003) Interleukin-23 rather than interleukin-12 is the critical cytokine for autoimmune inflammation of the brain. Nature 421:744-748

92. Korn T, Bettelli E, Oukka M, Kuchroo VK (2009) IL-17 and Th17 Cells. Annu Rev Immunol 27:485-517

93. Hofstetter $\mathrm{HH}$ et al (2005) Therapeutic efficacy of IL-17 neutralization in murine experimental autoimmune encephalomyelitis. Cell Immunol 237:123-130

94. Komiyama Y et al (2006) IL-17 plays an important role in the development of experimental autoimmune encephalomyelitis. J Immunol 177:566-573

95. Haak S et al (2009) IL-17A and IL-17F do not contribute vitally to autoimmune neuro-inflammation in mice. J Clin Invest 119:61-69

96. Kreymborg K et al (2007) IL-22 is expressed by Th17 cells in an IL-23-dependent fashion, but not required for the development of autoimmune encephalomyelitis. J Immunol 179:8098-8104

97. McGeachy MJ et al (2009) The interleukin 23 receptor is essential for the terminal differentiation of interleukin 17-producing effector T helper cells in vivo. Nat Immunol 10:314-324

98. Gyülvészi G, Haak S, Becher B (2009) Eur J Immunol 39(7): 1864-1869

99. Hickey WF (2001) Basic principles of immunological surveillance of the normal central nervous system. Glia 36:118-124

100. Bechmann I, Galea I, Perry VH (2007) What is the blood-brain barrier (not)? Trends Immunol 28:5-11

101. Suidan GL, McDole JR, Chen Y, Pirko I, Johnson AJ (2008) Induction of blood brain barrier tight junction protein alterations by CD8 T cells. PLoS ONE 3:e3037

102. Parathath SR, Parathath S, Tsirka SE (2006) Nitric oxide mediates neurodegeneration and breakdown of the blood-brain barrier in tPA-dependent excitotoxic injury in mice. J Cell Sci 119:339-349

103. Yepes $\mathrm{M}$ et al (2003) Tissue-type plasminogen activator induces opening of the blood-brain barrier via the LDL receptor-related protein. J Clin Invest 112:1533-1540
104. Coisne C, Mao W, Engelhardt B (2009) Cutting edge: natalizumab blocks adhesion but not initial contact of human $\mathrm{T}$ cells to the blood-brain barrier in vivo in an animal model of multiple sclerosis. J Immunol 182:5909-5913

105. Doring A, Wild M, Vestweber D, Deutsch U, Engelhardt B (2007) E- and P-selectin are not required for the development of experimental autoimmune encephalomyelitis in C57BL/6 and SJL mice. J Immunol 179:8470-8479

106. Kerfoot SM, Kubes P (2002) Overlapping roles of P-selectin and alpha 4 integrin to recruit leukocytes to the central nervous system in experimental autoimmune encephalomyelitis. J Immunol 169:1000-1006

107. Vajkoczy P, Laschinger M, Engelhardt B (2001) Alpha4integrin-VCAM-1 binding mediates $\mathrm{G}$ protein-independent capture of encephalitogenic $\mathrm{T}$ cell blasts to CNS white matter microvessels. J Clin Invest 108:557-565

108. Bullard DC et al (2007) Intercellular adhesion molecule-1 expression is required on multiple cell types for the development of experimental autoimmune encephalomyelitis. J Immunol 178:851-857

109. Cayrol R et al (2008) Activated leukocyte cell adhesion molecule promotes leukocyte trafficking into the central nervous system. Nat Immunol 9:137-145

110. Polman $\mathrm{CH}$ et al (2006) A randomized, placebo-controlled trial of natalizumab for relapsing multiple sclerosis. N Engl J Med 354:899-910

111. Rudick RA et al (2006) Natalizumab plus interferon beta-1a for relapsing multiple sclerosis. N Engl J Med 354:911-923

112. Wu C et al (2009) Endothelial basement membrane laminin alpha5 selectively inhibits $\mathrm{T}$ lymphocyte extravasation into the brain. Nat Med 15:519-527

113. Alt C, Laschinger M, Engelhardt B (2002) Functional expression of the lymphoid chemokines CCL19 (ELC) and CCL 21 (SLC) at the blood-brain barrier suggests their involvement in Gprotein-dependent lymphocyte recruitment into the central nervous system during experimental autoimmune encephalomyelitis. Eur J Immunol 32:2133-2144

114. Toft-Hansen $\mathrm{H}$ et al (2006) Metalloproteinases control brain inflammation induced by pertussis toxin in mice overexpressing the chemokine CCL2 in the central nervous system. J Immunol 177:7242-7249

115. Babcock AA, Kuziel WA, Rivest S, Owens T (2003) Chemokine expression by glial cells directs leukocytes to sites of axonal injury in the CNS. J Neurosci 23:7922-7930

116. Glabinski AR, Tani M, Tuohy VK, Tuthill RJ, Ransohoff RM (1995) Central nervous system chemokine mRNA accumulation follows initial leukocyte entry at the onset of acute murine experimental autoimmune encephalomyelitis. Brain Behav Immun 9:315-330

117. Agrawal S et al (2006) Dystroglycan is selectively cleaved at the parenchymal basement membrane at sites of leukocyte extravasation in experimental autoimmune encephalomyelitis. J Exp Med 203:1007-1019

118. Hafler DA et al (2007) Risk alleles for multiple sclerosis identified by a genome wide study. N Engl J Med 357:851-862

119. Steinman L (1996) Multiple sclerosis: a coordinated immunological attack against myelin in the central nervous system. Cell 85:299-302

120. Hauser SL et al (1986) Immunohistochemical analysis of the cellular infiltrate in multiple sclerosis lesions. Ann Neurol 19:578-587

121. Booss J, Esiri MM, Tourtellotte WW, Mason DY (1983) Immunohistological analysis of $\mathrm{T}$ lymphocyte subsets in the central nervous system in chronic progressive multiple sclerosis. J Neurol Sci 62:219-232

122. Crawford MP et al (2004) High prevalence of autoreactive, neuroantigen-specific CD8+ T cells in multiple sclerosis revealed by novel flow cytometric assay. Blood 103:4222-4231 
123. Jiang H, Braunstein NS, Yu B, Winchester R, Chess L (2001) CD8+ T cells control the TH phenotype of MBP-reactive CD4+ T cells in EAE mice. Proc Natl Acad Sci U S A 98:6301-6306

124. Babbe $\mathrm{H}$ et al (2000) Clonal expansions of CD8(+) $\mathrm{T}$ cells dominate the $\mathrm{T}$ cell infiltrate in active multiple sclerosis lesions as shown by micromanipulation and single cell polymerase chain reaction. J Exp Med 192:393-404

125. Ji Q, Goverman J (2007) Experimental autoimmune encephalomyelitis mediated by CD8+ T cells. Ann N Y Acad Sci 1103:157-166

126. Ford ML, Evavold BD (2005) Specificity, magnitude, and kinetics of MOG-specific CD8 $+\mathrm{T}$ cell responses during experimental autoimmune encephalomyelitis. Eur J Immunol 35:76-85

127. Najafian $\mathrm{N}$ et al (2003) Regulatory functions of CD8+CD28- T cells in an autoimmune disease model. J Clin Invest 112:1037-1048

128. Jiang $\mathrm{H}$ et al (2003) Regulatory CD8+ $\mathrm{T}$ cells fine-tune the myelin basic protein-reactive $\mathrm{T}$ cell receptor $\mathrm{V}$ beta repertoire during experimental autoimmune encephalomyelitis. Proc Natl Acad Sci U S A 100:8378-8383

129. Jiang H, Zhang SI, Pernis B (1992) Role of CD8+ T cells in murine experimental allergic encephalomyelitis. Science 256:1213-1215

130. Medana I, Martinic MA, Wekerle H, Neumann H (2001) Transection of major histocompatibility complex class I-induced neurites by cytotoxic T lymphocytes. Am J Pathol 159:809-815

131. Su SB et al (2005) Essential role of the MyD88 pathway, but nonessential roles of TLRs 2, 4, and 9, in the adjuvant effect promoting Th1-mediated autoimmunity. J Immunol 175:63036310

132. Yip HC et al (1999) Adjuvant-guided type-1 and type-2 immunity: infectious/noninfectious dichotomy defines the class of response. J Immunol 162:3942-3949

133. Brisebois M, Zehntner SP, Estrada J, Owens T, Fournier S (2006) A pathogenic role for $\mathrm{CD} 8+\mathrm{T}$ cells in a spontaneous model of demyelinating disease. J Immunol 177:2403-2411

134. Ip CW et al (2006) Immune cells contribute to myelin degeneration and axonopathic changes in mice overexpressing proteolipid protein in oligodendrocytes. J Neurosci 26:8206-8216

135. Cornet A et al (2001) Enterocolitis induced by autoimmune targeting of enteric glial cells: a possible mechanism in Crohn's disease? Proc Natl Acad Sci U S A 98:13306-13311

136. Cabarrocas J, Bauer J, Piaggio E, Liblau R, Lassmann H (2003) Effective and selective immune surveillance of the brain by MHC class I-restricted cytotoxic T lymphocytes. Eur J Immunol 33:1174-1182

137. Perchellet A, Stromnes I, Pang JM, Goverman J (2004) CD8+ T cells maintain tolerance to myelin basic protein by 'epitope theft'. Nat Immunol 5:606-614

138. Baur $\mathrm{K}$ et al (2008) Antiviral CD8 $\mathrm{T}$ cells recognize Borna disease virus antigen transgenically expressed in either neurons or astrocytes. J Virol 82:3099-3108

139. Saxena A et al (2008) Cutting edge: multiple sclerosis-like lesions induced by effector CD8 $\mathrm{T}$ cells recognizing a sequestered antigen on oligodendrocytes. J Immunol 181:1617-1621

140. Galea I et al (2007) An antigen-specific pathway for CD8 T cells across the blood-brain barrier. J Exp Med 204:2023-2030

141. Na SY et al (2008) Naive CD8 T-cells initiate spontaneous autoimmunity to a sequestered model antigen of the central nervous system. Brain 131:2353-2365

142. Mars LT et al (2007) CD8 T cell responses to myelin oligodendrocyte glycoprotein-derived peptides in humanized HLA-A*0201-transgenic mice. J Immunol 179:5090-5098

143. Friese MA et al (2008) Opposing effects of HLA class I molecules in tuning autoreactive $\mathrm{CD} 8+\mathrm{T}$ cells in multiple sclerosis. Nat Med 14:1227-1235

144. Munz C, Lunemann JD, Getts MT, Miller SD (2009) Antiviral immune responses: triggers of or triggered by autoimmunity? Nat Rev Immunol 9:246-258
145. Evans CF, Horwitz MS, Hobbs MV, Oldstone MB (1996) Viral infection of transgenic mice expressing a viral protein in oligodendrocytes leads to chronic central nervous system autoimmune disease. J Exp Med 184:2371-2384

146. Olson JK, Croxford JL, Calenoff MA, Dal Canto MC, Miller SD (2001) A virus-induced molecular mimicry model of multiple sclerosis. J Clin Invest 108:311-8

147. Butz EA, Bevan MJ (1998) Massive expansion of antigenspecific $\mathrm{CD} 8+\mathrm{T}$ cells during an acute virus infection. Immunity $8: 167-175$

148. Murali-Krishna K et al (1998) Counting antigen-specific CD8 T cells: a reevaluation of bystander activation during viral infection. Immunity 8:177-187

149. Croxford JL, Ercolini AM, Degutes M, Miller SD (2006) Structural requirements for initiation of cross-reactivity and CNS autoimmunity with a PLP139-151 mimic peptide derived from murine hepatitis virus. Eur J Immunol 36:2671-2680

150. Haring JS, Pewe LL, Perlman S (2002) Bystander CD8 T cellmediated demyelination after viral infection of the central nervous system. J Immunol 169:1550-1555

151. Dandekar AA, Anghelina D, Perlman S (2004) Bystander CD8 T-cell-mediated demyelination is interferon-gamma-dependent in a coronavirus model of multiple sclerosis. Am J Pathol 164:363369

152. Ercolini AM, Miller SD (2009) The role of infections in autoimmune disease. Clin Exp Immunol 155:1-15

153. Dal Canto MC, Lipton HL (1975) Primary demyelination in Theiler's virus infection. An ultrastructural study. Lab Invest 33:626-637

154. Lipton HL (1975) Theiler's virus infection in mice: an unusual biphasic disease process leading to demyelination. Infect Immun 11:1147-1155

155. Dal Canto MC, Lipton HL (1982) Ultrastructural immunohistochemical localization of virus in acute and chronic demyelinating Theiler's virus infection. Am J Pathol 106:20-29

156. Lipton HL, Twaddle G, Jelachich ML (1995) The predominant virus antigen burden is present in macrophages in Theiler's murine encephalomyelitis virus-induced demyelinating disease. J Virol 69:2525-2533

157. Trottier M, Kallio P, Wang W, Lipton HL (2001) High numbers of viral RNA copies in the central nervous system of mice during persistent infection with Theiler's virus. J Virol 75:7420-7428

158. Aubert C, Chamorro M, Brahic M (1987) Identification of Theiler's virus infected cells in the central nervous system of the mouse during demyelinating disease. Microb Pathog 3:319-326

159. Rodriguez M, Leibowitz JL, Lampert PW (1983) Persistent infection of oligodendrocytes in Theiler's virus-induced encephalomyelitis. Ann Neurol 13:426-433

160. Zheng L, Calenoff MA, Dal Canto MC (2001) Astrocytes, not microglia, are the main cells responsible for viral persistence in Theiler's murine encephalomyelitis virus infection leading to demyelination. J Neuroimmunol 118:256-267

161. Rodriguez M (1985) Virus-induced demyelination in mice: "dying back" of oligodendrocytes. Mayo Clin Proc 60:433-438

162. Roos RP, Wollmann R (1984) DA strain of Theiler's murine encephalomyelitis virus induces demyelination in nude mice. Ann Neurol 15:494-499

163. Kang MH, So EY, Park H, Kim BS (2008) Replication of Theiler's virus requires NF-kappa B-activation: higher viral replication and spreading in astrocytes from susceptible mice. Glia 56:942-953

164. Palma JP, Kim BS (2004) The scope and activation mechanisms of chemokine gene expression in primary astrocytes following infection with Theiler's virus. J Neuroimmunol 149:121-129

165. Palma JP, Kwon D, Clipstone NA, Kim BS (2003) Infection with Theiler's murine encephalomyelitis virus directly induces proin- 
flammatory cytokines in primary astrocytes via NF-kappa B activation: potential role for the initiation of demyelinating disease. J Virol 77:6322-6331

166. So EY, Kang MH, Kim BS (2006) Induction of chemokine and cytokine genes in astrocytes following infection with Theiler's murine encephalomyelitis virus is mediated by the Toll-like receptor 3. Glia 53:858-867

167. So EY, Kim BS (2009) Theiler's virus infection induces TLR3dependent upregulation of TLR2 critical for proinflammatory cytokine production. Glia 57:1216-1226

168. Carpentier PA, Williams BR, Miller SD (2007) Distinct roles of protein kinase $\mathrm{R}$ and toll-like receptor 3 in the activation of astrocytes by viral stimuli. Glia 55:239-252

169. Croxford JL, Olson JK, Miller SD (2002) Epitope spreading and molecular mimicry as triggers of autoimmunity in the Theiler's virus-induced demyelinating disease model of multiple sclerosis. Autoimmun Rev 1:251-260

170. Miller SD et al (1997) Persistent infection with Theiler's virus leads to CNS autoimmunity via epitope spreading. Nat Med 3:1133-1136

171. Vanderlugt CL, Miller SD (2002) Epitope spreading in immunemediated diseases: implications for immunotherapy. Nat Rev Immunol 2:85-95

172. Katz-Levy Y et al (2000) Temporal development of autoreactive Th1 responses and endogenous presentation of self myelin epitopes by central nervous system-resident APCs in Theiler's virus-infected mice. J Immunol 165:5304-5314

173. Brahic M, Bureau JF, Michiels T (2005) The genetics of the persistent infection and demyelinating disease caused by Theiler's virus. Annu Rev Microbiol 59:279-298

174. Lipton HL, Melvold R (1984) Genetic analysis of susceptibility to Theiler's virus-induced demyelinating disease in mice. J Immunol 132:1821-1825

175. Borrow P, Tonks P, Welsh CJ, Nash AA (1992) The role of CD8+T cells in the acute and chronic phases of Theiler's murine encephalomyelitis virus-induced disease in mice. J Gen Virol 73 (Pt 7):1861-1865

176. Fiette L, Aubert C, Brahic M, Rossi CP (1993) Theiler's virus infection of beta 2-microglobulin-deficient mice. J Virol 67:589592

177. Ure DR, Rodriguez M (2002) Preservation of neurologic function during inflammatory demyelination correlates with axon sparing in a mouse model of multiple sclerosis. Neuroscience 111:399-411

178. Begolka WS et al (2001) CD8-deficient SJL mice display enhanced susceptibility to Theiler's virus infection and increased demyelinating pathology. J Neurovirol 7:409-420

179. Howe CL et al (2007) CD8 + T cells directed against a viral peptide contribute to loss of motor function by disrupting axonal transport in a viral model of fulminant demyelination. J Neuroimmunol 188:13-21

180. Howe CL, Adelson JD, Rodriguez M (2007) Absence of perforin expression confers axonal protection despite demyelination. Neurobiol Dis 25:354-359

181. Woodruff RH, Franklin RJ (1999) Demyelination and remyelination of the caudal cerebellar peduncle of adult rats following stereotaxic injections of lysolecithin, ethidium bromide, and complement/anti-galactocerebroside: a comparative study. Glia $25: 216-228$

182. Matsushima GK, Morell P (2001) The neurotoxicant, cuprizone, as a model to study demyelination and remyelination in the central nervous system. Brain Pathol 11:107-116

183. Taylor LC, Gilmore W, Matsushima GK (2008) SJL mice exposed to cuprizone intoxication reveal strain and gender pattern differences in demyelination. Brain Pathol 19:467-479

184. Suzuki K (1969) Giant hepatic mitochondria: production in mice fed with cuprizone. Science 163:81-82
185. Blakemore WF (1973) Remyelination of the superior cerebellar peduncle in the mouse following demyelination induced by feeding cuprizone. J Neurol Sci 20:73-83

186. Skripuletz T et al (2008) Cortical demyelination is prominent in the murine cuprizone model and is strain-dependent. Am J Pathol 172:1053-1061

187. Hoffmann K, Lindner M, Groticke I, Stangel M, Loscher W (2008) Epileptic seizures and hippocampal damage after cuprizone-induced demyelination in C57BL/6 mice. Exp Neurol 210:308-321

188. Koutsoudaki PN et al (2009) Demyelination of the hippocampus is prominent in the cuprizone model. Neurosci Lett 451:83-88

189. Irvine KA, Blakemore WF (2006) Age increases axon loss associated with primary demyelination in cuprizone-induced demyelination in C57BL/6 mice. J Neuroimmunol 175:69-76

190. Mason JL, Langaman C, Morell P, Suzuki K, Matsushima GK (2001) Episodic demyelination and subsequent remyelination within the murine central nervous system: changes in axonal calibre. Neuropathol Appl Neurobiol 27:50-58

191. Irvine KA, Blakemore WF (2008) Remyelination protects axons from demyelination-associated axon degeneration. Brain 131:1464-1477

192. Jurevics $\mathrm{H}$ et al (2001) Cerebroside synthesis as a measure of the rate of remyelination following cuprizone-induced demyelination in brain. J Neurochem 77:1067-1076

193. Wu QZ et al (2008) MRI identification of the rostral-caudal pattern of pathology within the corpus callosum in the cuprizone mouse model. J Magn Reson Imaging 27:446-453

194. Mason JL et al (2000) Mature oligodendrocyte apoptosis precedes IGF-1 production and oligodendrocyte progenitor accumulation and differentiation during demyelination/remyelination. J Neurosci Res 61:251-262

195. Lindner $M$ et al (2008) Sequential myelin protein expression during remyelination reveals fast and efficient repair after central nervous system demyelination. Neuropathol Appl Neurobiol 34:105-114

196. Kondo A, Nakano T, Suzuki K (1987) Blood-brain barrier permeability to horseradish peroxidase in twitcher and cuprizone-intoxicated mice. Brain Res 425:186-190

197. McMahon EJ, Suzuki K, Matsushima GK (2002) Peripheral macrophage recruitment in cuprizone-induced CNS demyelination despite an intact blood-brain barrier. J Neuroimmunol 130:32-45

198. Hiremath MM et al (1998) Microglial/macrophage accumulation during cuprizone-induced demyelination in C57BL/6 mice. J Neuroimmunol 92:38-49

199. Remington LT, Babcock AA, Zehntner SP, Owens T (2007) Microglial recruitment, activation, and proliferation in response to primary demyelination. Am J Pathol 170:1713-1724

200. Arnett HA et al (2001) TNF alpha promotes proliferation of oligodendrocyte progenitors and remyelination. Nat Neurosci 4:1116-1122

201. Hiremath MM, Chen VS, Suzuki K, Ting JP, Matsushima GK (2008) MHC class II exacerbates demyelination in vivo independently of T cells. J Neuroimmunol 203:23-32

202. Arnett HA, Wang Y, Matsushima GK, Suzuki K, Ting JP (2003) Functional genomic analysis of remyelination reveals importance of inflammation in oligodendrocyte regeneration. J Neurosci 23:9824-9832

203. Kotter MR, Setzu A, Sim FJ, Van Rooijen N, Franklin RJ (2001) Macrophage depletion impairs oligodendrocyte remyelination following lysolecithin-induced demyelination. Glia 35:204212

204. Mana P, Linares D, Fordham S, Staykova M, Willenborg D (2006) Deleterious role of IFN gamma in a toxic model of central nervous system demyelination. Am J Pathol 168:1464-1473 
205. Lin W et al (2006) Interferon-gamma inhibits central nervous system remyelination through a process modulated by endoplasmic reticulum stress. Brain 129:1306-1318

206. Trebst $\mathrm{C}$ et al (2007) Lack of interferon-beta leads to accelerated remyelination in a toxic model of central nervous system demyelination. Acta Neuropathol 114:587-596

207. Marriott MP et al (2008) Leukemia inhibitory factor signaling modulates both central nervous system demyelination and myelin repair. Glia 56:686-698

208. Plant SR, Arnett HA, Ting JP (2005) Astroglial-derived lymphotoxin-alpha exacerbates inflammation and demyelination, but not remyelination. Glia 49:1-14

209. Plant SR et al (2007) Lymphotoxin beta receptor (Lt beta R): dual roles in demyelination and remyelination and successful therapeutic intervention using Lt beta R-Ig protein. J Neurosci 27:7429-7437

210. Mason JL, Suzuki K, Chaplin DD, Matsushima GK (2001) Interleukin-1 beta promotes repair of the CNS. J Neurosci 21 (18):7046-7052

211. Mason JL, Xuan S, Dragatsis I, Efstratiadis A, Goldman JE (2003) Insulin-like growth factor (IGF) signaling through type 1 IGF receptor plays an important role in remyelination. J Neurosci 23(20):7710-7718

212. Linares D, Taconis M, Mana P, Correcha M, Fordham S, Staykova M, Willenborg DO (2006) Neuronal nitric oxide synthase plays a key role in CNS demyelination. J Neurosci 26 (49):12672-12681

213. Arnett HA, Hellendall RP, Matsushima GK, Suzuki K, Laubach VE, Sherman P, Ting JP (2002) The protective role of nitric oxide in a neurotoxicant-induced demyelinating model. J Immunol 168(1):427-433

214. McMahon EJ, Cook DN, Suzuki K, Matsushima GK (2001) Absence of macrophage-inflammatory protein-1alpha delays central nervous system demyelination in the presence of an intact blood-brain barrier. J Immunol 167(5):2964-2971

215. Franco-Pons N, Torrente M, Colomina MT, Vilella E (2007) Behavioral deficits in the cuprizone-induced murine model of demyelination/remyelination. Toxicol Lett 169:205-213

216. Liebetanz D, Merkler D (2006) Effects of commissural de- and remyelination on motor skill behaviour in the cuprizone mouse model of multiple sclerosis. Exp Neurol 202:217-224

217. Andersson PB, Perry VH, Gordon S (1992) The acute inflammatory response to lipopolysaccharide in CNS parenchy- ma differs from that in other body tissues. Neuroscience 48:169186

218. Bell MD, Perry VH (1995) Adhesion molecule expression on murine cerebral endothelium following the injection of a proinflammagen or during acute neuronal degeneration. J Neurocytol 24:695-710

219. Felts PA et al (2005) Inflammation and primary demyelination induced by the intraspinal injection of lipopolysaccharide. Brain 128:1649-1666

220. Marik C, Felts PA, Bauer J, Lassmann H, Smith KJ (2007) Lesion genesis in a subset of patients with multiple sclerosis: a role for innate immunity? Brain 130:2800-2815

221. Ji KA et al (2007) Resident microglia die and infiltrated neutrophils and monocytes become major inflammatory cells in lipopolysaccharide-injected brain. Glia 55:1577-1588

222. Andersson PB, Perry VH, Gordon S (1992) Intracerebral injection of proinflammatory cytokines or leukocyte chemotaxins induces minimal myelomonocytic cell recruitment to the parenchyma of the central nervous system. J Exp Med 176:255259

223. Zhou H, Lapointe BM, Clark SR, Zbytnuik L, Kubes P (2006) A requirement for microglial TLR4 in leukocyte recruitment into brain in response to lipopolysaccharide. J Immunol 177:81038110

224. Lehnardt S et al (2002) The toll-like receptor TLR4 is necessary for lipopolysaccharide-induced oligodendrocyte injury in the CNS. J Neurosci 22:2478-2486

225. Li J, Baud O, Vartanian T, Volpe JJ, Rosenberg PA (2005) Peroxynitrite generated by inducible nitric oxide synthase and NADPH oxidase mediates microglial toxicity to oligodendrocytes. Proc Natl Acad Sci U S A 102:9936-9941

226. Pang Y, Cai Z, Rhodes PG (2000) Effects of lipopolysaccharide on oligodendrocyte progenitor cells are mediated by astrocytes and microglia. J Neurosci Res 62:510-520

227. Li J et al (2008) Tumor necrosis factor alpha mediates lipopolysaccharide-induced microglial toxicity to developing oligodendrocytes when astrocytes are present. J Neurosci 28:53215330

228. Brockschnieder D, Pechmann Y, Sonnenberg-Riethmacher E, Riethmacher D (2006) An improved mouse line for Cre-induced cell ablation due to diphtheria toxin A, expressed from the Rosa26 locus. Genesis 44:322-327 